\title{
ARTICLE OPEN \\ A DL-4- and TNF $\alpha$-based culture system to generate high numbers of nonmodified or genetically modified immunotherapeutic human T-lymphoid progenitors
}

\author{
Ranjita Devi Moirangthem ${ }^{1}$, Kuiying Ma ${ }^{1}$, Sabrina Lizot ${ }^{1}$, Anne Cordesse ${ }^{1}$, Juliette Olivré (iD) ${ }^{1}$, Corinne de Chappedelaine ${ }^{1}$, Akshay Joshi ${ }^{1}$, \\ Agata Cieslak $\mathbb{D}^{2,3}$, John Tchen ${ }^{1}$, Nicolas Cagnard ${ }^{4}$, Vahid Asnafi ${ }^{2,3}$, Antonio Rausell $\mathbb{1}^{5}$, Laura Simons ${ }^{6}$, Julien Zuber ${ }^{1,7}$, \\ Tom Taghon $\mathbb{D}^{8,9}$, Frank J. T. Staal ${ }^{10}$, Françoise Pflumio ${ }^{11}$, Emmanuelle Six ${ }^{1}$, Marina Cavazzana ${ }^{1,6}$, Chantal Lagresle-Peyrou ${ }^{1,6}$, \\ Tayebeh Soheili ${ }^{1}$ and Isabelle André ${ }^{1}$
}

\begin{abstract}
Several obstacles to the production, expansion and genetic modification of immunotherapeutic T cells in vitro have restricted the widespread use of T-cell immunotherapy. In the context of HSCT, delayed naïve T-cell recovery contributes to poor outcomes. A novel approach to overcome the major limitations of both T-cell immunotherapy and HSCT would be to transplant human Tlymphoid progenitors (HTLPs), allowing reconstitution of a fully functional naïve T-cell pool in the patient thymus. However, it is challenging to produce HTLPs in the high numbers required to meet clinical needs. Here, we found that adding tumor necrosis factor alpha (TNFa) to a DL-4-based culture system led to the generation of a large number of nonmodified or genetically modified HTLPs possessing highly efficient in vitro and in vivo T-cell potential from either CB HSPCs or mPB HSPCs through accelerated T-cell differentiation and enhanced HTLP cell cycling and survival. This study provides a clinically suitable cell culture platform to generate high numbers of clinically potent nonmodified or genetically modified HTLPs for accelerating immune recovery after HSCT and for T-cell-based immunotherapy (including CAR T-cell therapy).
\end{abstract}

Keywords: Human T-lymphoid progenitor; Tumor necrosis factor alpha; Delta-like ligand 4; Hematopoietic stem and progenitor cells; Mobilized peripheral blood

Cellular \& Molecular Immunology (2021) 18:1662-1676; https://doi.org/10.1038/s41423-021-00706-8

\section{INTRODUCTION}

T cells are the armed wing of the immune system that protect against viruses and cancer cells. Genetically engineered T cells (and particularly specific chimeric antigen receptor (CAR)-expressing T cells), mostly adult, now constitute an essential tool for Tcell immunotherapy (e.g., the treatment of lymphoma and HIV infection). ${ }^{1,2}$ Beyond effector $\mathrm{T}$ cells, regulatory $\mathrm{T}$ cells (Tregs, including CAR Tregs) have also been used to induce immune tolerance in the contexts of autoimmune diseases, graft-versushost disease, transplant rejection, and hypersensitivity reactions., However, in all cases, the manufacture of clinically relevant, genetically modified CAR T cells is cumbersome and challenging. Cell preparation often takes several weeks, which restricts the use of this approach in patients with rapidly progressing disease. ${ }^{5}$ Furthermore, it is difficult to generate sufficient doses of clinically relevant CAR-T cells from patients who have been extensively treated with chemotherapeutic and antineoplastic drugs. The use of allogenic $T$ cells is currently being explored but requires additional treatments to avoid graft-versus-host disease. ${ }^{6}$ In addition to the challenges of producing CAR T cells quickly, the use of these T cells is also associated with adverse events, such as cytokine release syndrome and neurotoxicity, and their clinical efficacy is limited by exhaustion. ${ }^{7}$ A novel alternative approach to CAR T-cell immunotherapy would involve the in vitro generation of genetically modified T-cell progenitors that could differentiate into naïve $\mathrm{T}$ cells upon transplantation into the patient. In a completely different clinical setting, poor or delayed naïve T-cell reconstitution following allogeneic hematopoietic stem cell transplantation (HSCT) is a limitation that exposes the patient to an elevated risk of severe and frequently lethal infections. ${ }^{8-11}$ In

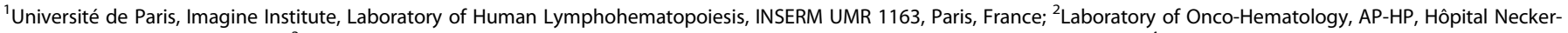

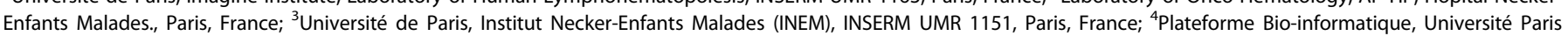

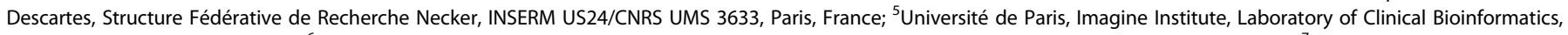

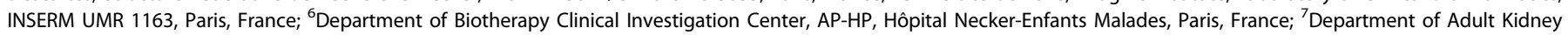

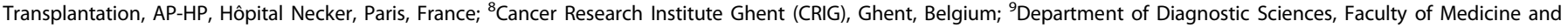

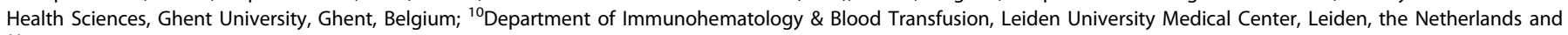

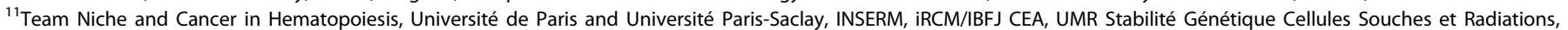
Fontenay-aux-Roses, France

Correspondence: Isabelle André (isabelle.andre@inserm.fr)

These authors contributed equally: Ranjita Devi Moirangthem, Kuiying Ma

These authors jointly supervised this work: Tayebeh Soheili, Isabelle André

Received: 27 October 2020 Accepted: 11 May 2021

Published online: 11 June 2021 
this context, the cotransplantation of human T-lymphoid progenitors (HTLPs) and hematopoietic stem and progenitor cells (HSPCs) from a conventional graft might overcome this issue by accelerating T-cell reconstitution. In light of the above information, there is an urgent need to develop a cell culture platform that can produce large numbers of clinically potent nonmodified or genetically modified immunotherapeutic HTLPs capable of rapidly reconstituting a broad subset of naïve T cells with multiple repertoires after transplantation.

In mice and humans, the early stages of T-cell development are dependent on Notch signaling (particularly signaling via delta-like ligand $4(\mathrm{DL}-4))^{12-14}$ and key cytokines involved in thymocyte survival and proliferation. ${ }^{15-17}$ In humans, T-cell development is typically initiated by the acquisition of surface CD7, ${ }^{18}$ which is followed by CD5 expression. Next, CD7- and CD5-expressing precursors give rise to a CD1a-expressing subset, which constitutes the fully committed T-cell precursors. ${ }^{19}$ We previously implemented a stromal cell-free culture system based on immobilized DL-4 (Notch ligand) to generate $C D 7^{+}$HTLPs from either cord blood (CB) HSPCs or mobilized peripheral blood (mPB) HSPCs during a 7-day period of culture..$^{20,21}$ These progenitors displayed the phenotype and molecular signature of very immature thymic progenitors and expressed T-lineage transcriptional regulators (TCF7, IL7Ra, BCL11B, GATA3, and CD3E). Upon transplantation into irradiated adult or nonirradiated neonate $\mathrm{NOD} / \mathrm{SCID} / \mathrm{YC}^{-1-}$ (NSG) recipients, HTLPs seeded the thymus and generated mature, polyclonal and functional T cells. ${ }^{20,21}$ Cotransplantation of HTLPs generated in vitro and nonmanipulated $\mathrm{CD}_{3} 4^{+} \mathrm{HSPCs}$ led to robust, rapid reconstitution of the T-cell compartment, while the other hematopoietic lineages arose from the nonmanipulated HSPCs. ${ }^{20}$

Mobilized peripheral blood is currently the main source of HSPCs for allogenic HSCT due to its availability in large quantities. Although mPB HSPCs have several advantages over CB HSPCs in clinical settings, they are less able to differentiate into lymphoid lineages (particularly the T-cell lineage). ${ }^{22}$ Moreover, fewer HTLPs were generated by culturing mPB HSPCs in our immobilized DL-4 system than by culturing $C B$ HSPCs, possibly due to intrinsic differences in T-cell potential, survival and proliferation. This low yield was accompanied by a higher apoptosis rate, a lower proliferation rate, and less efficient, delayed reconstitution of mature T cells upon transplantation into NSG mice. ${ }^{21}$ Therefore, we decided to screen for potent molecules that could improve the cell expansion and yield of HTLPs in our culture system, with a main focus on mPB. Based on our literature search, we selected StemReginin 1 (SR1) (an aryl hydrocarbon receptor antagonist), UM171 and UM729 (pyrimidoindole derivatives), tumor necrosis factor alpha (TNFa) and 2-phospho-L-ascorbic acid (Ph-AA) for screening. SR1, UM171 and UM729 are known to promote human hematopoietic stem cell (HSC) expansion. ${ }^{23-25}$ In contrast, Ph-AA and TNFa were previously reported to promote the in vitro T-cell potential of human HSCs and HSPCs. ${ }^{26-28}$ We found that the addition of TNFa dramatically increased the yield of CD7 ${ }^{+}$HTLPs derived from either CB HSPCs or adult mPB HSPCs and the purity of the final cell product (an average of $>80 \%$ of $C D 7^{+}$cells for $\mathrm{CB}$ and $>70 \%$ for $\mathrm{mPB}$ ). We further demonstrated that this increase in yield was due to greater cell proliferation and enhanced cell survival (through decreased apoptosis) of $C D 7^{+}$HTLPs specifically. Surprisingly, TNFa also enhanced the in vitro and in vivo T-cell potential of CB or MPB HTLPs.

Even though TNFa has an antiviral effect, we further demonstrated that (i) CB or MPB HSPCs could be transduced in a TNFasupplemented $\mathrm{DL}-4$ culture system to generate genetically modified CB or MPB HSPC-derived T-cell progenitors and (ii) the addition of TNFa enhanced the yields of transduced HTLPs by factors of 4.3- and 10.5-fold for CB and MPB, respectively. Last, we demonstrated the enhanced in vitro and in vivo T-cell potential of TNFa-exposed transduced HTLPs.
Thus, our TNFa-supplemented DL-4 culture system constitutes an efficient platform for the in vitro production of functional nonmodified or genetically modified HTLPs that possess the clinical potential to accelerate T-cell reconstitution after HSCT (to be tested in the forthcoming clinical trial NCT03879876) and to be effective as a CAR T-cell-based immunotherapy for treating a variety of diseases.

\section{MATERIALS AND METHODS}

Human samples

Following the provision of informed consent, umbilical CB samples were collected via ethically approved procedures from donors at Saint Louis Hospital (Paris, France). The mPB samples used were the unused fraction of grafts from healthy donors mobilized with granulocyte colony-stimulating factor who provided informed consent for research use. The mPB samples were part of a collection authorized by the French Ministry of Research (reference: DC-2014-2272, dated March 23rd, 2015). Cord blood and $\mathrm{mPB} \mathrm{CD} 34^{+} \mathrm{HSPCs}$ were magnetically enriched (purity $>93 \%$ ) from $C B$ and $\mathrm{mPB}$ samples, respectively, as described previously. ${ }^{29}$

\section{Cell cultures}

For screening of various molecules, human $\mathrm{CD}^{+} 4^{+} \mathrm{HSPCs}$ isolated from CB or mPB were cultured for 7 days at a cell concentration of $2 \times 10^{4} / \mathrm{ml}$ in DL-4-Fc fusion protein $(5 \mu \mathrm{g} / \mathrm{ml})$ - and RetroNectin ${ }^{\circledR}$ $(25 \mu \mathrm{g} / \mathrm{ml}) \quad$ (Ozyme, Saint-Quentin-en-Yvelines, France)-coated wells of 24-well plates containing a-MEM (Gibco, Life Technologies, Carlsbad, CA) supplemented with $20 \%$ defined fetal bovine serum (HyClone, Thermo Fisher Scientific, Illkirch, France) and human cytokines $(100 \mathrm{ng} / \mathrm{ml}$ interleukin (IL)-7, $100 \mathrm{ng} / \mathrm{ml} \mathrm{FMS-like}$ tyrosine kinase 3 ligand (Flt3-L), $100 \mathrm{ng} / \mathrm{ml}$ stem cell factor (SCF) and $100 \mathrm{ng} / \mathrm{ml}$ thrombopoietin (TPO); all from PeproTech Inc., Rocky Hill, NJ) ${ }^{20,21}$ in the presence or absence of $100 \mu \mathrm{M}$ Ph-AA (Sigma-Aldrich, St. Louis, MO, USA), $750 \mathrm{nM}$ SR1 (Cayman Chemical, Ann Arbor, Michigan, United States), 35 nM UM171, 1

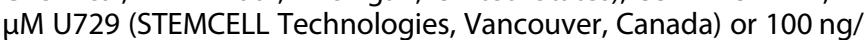
ml TNFa (R\&D Systems, Minneapolis, MN).

For cell cultures with or without TNFa used to generate HTLPs, human $\mathrm{CD}_{3} 4^{+} \mathrm{HSPCs}$ isolated from $\mathrm{CB}$ or $\mathrm{mPB}$ were cultured for 7 days at a cell concentration of $2 \times 10^{4} / \mathrm{ml}$ in DL-4-Fc fusion protein $(5 \mu \mathrm{g} / \mathrm{ml})-$ and RetroNectin ${ }^{\circledR}(25 \mu \mathrm{g} / \mathrm{ml})$ (Ozyme, SaintQuentin-en-Yvelines, France)-coated wells of 24- or 6-well plates containing a-MEM (Gibco, Life Technologies, Carlsbad, CA) supplemented with $20 \%$ defined fetal bovine serum (HyClone, Thermo Fisher Scientific, Illkirch, France) and human cytokines $(100 \mathrm{ng} / \mathrm{ml}$ interleukin 7 (IL)-7, $100 \mathrm{ng} / \mathrm{ml}$ FMS-like tyrosine kinase 3 ligand (Flt3-L), $100 \mathrm{ng} / \mathrm{ml}$ stem cell factor (SCF) and $100 \mathrm{ng} / \mathrm{ml}$ thrombopoietin (TPO); all from PeproTech Inc., Rocky Hill, NJ) ${ }^{20,21}$ in the presence or absence of $100 \mathrm{ng} / \mathrm{ml}$ TNFa (R\&D Systems, Minneapolis, MN).

For cell cultures with/without DL-4, $\mathrm{CD} 34^{+} \mathrm{CB}$ or $\mathrm{mPB} \mathrm{HSPCs}$ were cultured for 7 days at a cell concentration of $2 \times 10^{4} / \mathrm{ml}$ in wells of 24-well plates coated with either the DL-4-Fc fusion protein $(5 \mu \mathrm{g} / \mathrm{ml})$ and RetroNectin ${ }^{\circledR}(25 \mu \mathrm{g} / \mathrm{ml})$ or the Fc protein and RetroNectin ${ }^{\circledR}(25 \mu \mathrm{g} / \mathrm{ml})$ in a-MEM (Gibco, Life Technologies, Carlsbad, CA) supplemented with $20 \%$ defined fetal bovine serum (HyClone, Thermo Fisher Scientific, Illkirch, France) and human cytokines $(100 \mathrm{ng} / \mathrm{ml} \mathrm{IL-7,} 100 \mathrm{ng} / \mathrm{ml} \mathrm{Flt3-L,} 100 \mathrm{ng} / \mathrm{ml}$ SCF and $100 \mathrm{ng} / \mathrm{ml}$ TPO; all from PeproTech Inc., Rocky Hill, NJ) in the presence of $100 \mathrm{ng} / \mathrm{ml}$ TNFa (R\&D Systems, Minneapolis, MN).

\section{DL-4 cultures of HSPC subsets}

$\mathrm{CD} 4^{+} \mathrm{CD}^{+}{ }^{+}$cells, hematopoietic stem cells, multilymphoid progenitors (MLPs), and multipotent progenitors (MPPs) were sorted from CB CD34 ${ }^{+}$HSPCs. The sorted HSPC subsets were cultured for 7 days in DL-4-Fc fusion protein- $(5 \mu \mathrm{g} / \mathrm{ml})$ and RetroNectin ${ }^{\circledR}(25 \mu \mathrm{g} / \mathrm{ml})$ (Ozyme)-coated wells of 96 -well plates 
(4000 cells/well) containing a-MEM (Gibco) supplemented with $20 \%$ defined fetal bovine serum (HyClone) and human cytokines $(100 \mathrm{ng} / \mathrm{ml} \mathrm{IL-7,} 100 \mathrm{ng} / \mathrm{ml}$ Flt3-L, $100 \mathrm{ng} / \mathrm{ml} \mathrm{SCF}$ and $100 \mathrm{ng} / \mathrm{ml}$ TPO; all from PeproTech Inc.) in the presence or absence of 100 $\mathrm{ng} / \mathrm{ml}$ TNFa (R\&D Systems) (i.e., DL-4 culture conditions with or without TNFa).

\section{DL-4 cultures with an NFKB inhibitor}

$\mathrm{mPB} \mathrm{CD} 34^{+} \mathrm{HSPC} s$ were cultured in DL-4 conditions without TNFa for $5 \mathrm{~h}$. An NFKB inhibitor, piceatannol (R\&D Systems), was added to cultures at $25 \mu \mathrm{M}$. After $16 \mathrm{~h}$, TNFa was added at the usual concentration of $100 \mathrm{ng} / \mathrm{ml}$. On day 3, piceatannol was removed by replacement of the culture medium with fresh medium, and TNFa-supplemented DL-4 culture was continued to day 7 .

\section{Transduction}

$\mathrm{CB}$ or mPB CD34 ${ }^{+}$HSPCs were preactivated overnight on DL-4and RetroNectin ${ }^{\circledR}$-coated wells containing X-vivo 20 medium in the presence of DL- 4 culture cytokines and IL-3. The cells were then transduced under the same conditions with VSV-G pseudotyped lentiviruses encoding a GFP reporter protein at a multiplicity of infection (MOI) of 100. The transduced cells were then washed with a-MEM (Gibco) and cultured for a total of 7 days in the DL-4 culture system in the presence or absence of TNFa.

Flow cytometric analysis

Anti-human CD4-APC (clone REA623), CD4-APCVio770 (clone REA623), CD8-PEVio770 (clone REA734), CD8-APC (clone REA 734), CD34-APC (clone AC136), CD34-PECy7 (clone AC136), CD45-APCVio770 (clone REA747), CD45-PEVio770 (clone 747), CD133/1-Viobright FITC (AC133), CD3e-PE (intracellular) (clone REA975), GATA3-APC (clone REA174), CD120a (TNFRI)-PEVio770 (clone REA252), CD120b (TNFRII)-PE (clone REA520) and lineage cocktail-PE antibodies and 7-aminoactinomycin D (7-AAD) were obtained from Miltenyi Biotech (Bergisch Gladbach, Germany). Anti-human CD7-FITC (clone MT701), CD7-PE (clone MT701), CD5PE (clone UCHT2), CD38-APC (HIT2), CD90-PECy5 (5E10), NFkB p65 (pS529)-PE (clone K10-895.12.50) and Ki-67-PECy7 (clone B56) were purchased from BD Biosciences (San Jose, CA). Anti-human CD45-BV510 (clone H130), anti-CD3-BV421 (UCHT1), anti-CD45RABV421 (HI100) and anti-murine CD45-BV510 (clone 30F-11) antibodies were purchased from Sony Biotechnology (San Jose, CA). Anti-human CD34-APCCy7 (581), TCRaß-APC (IP26A), TCRaßPECy5 (IP26A) and Bcl-2-PE (clone 100) antibodies were purchased from BioLegend (San Diego, CA). Anti-human TCR $\gamma \delta$-FITC (IMMU510) and TCRYठ-PE (IMMU510) were purchased from Beckman Coulter (Brea, CA). An anti-human Bcl-11b (Ctip2)-FITC antibody (clone 25B6) was purchased from Abcam (Cambridge, UK), and an anti-human Mcl-1-Alexa Fluor 647 antibody (clone LVUBKM) was purchased from eBioscience (San Diego, CA).

For surface staining, cells were incubated with the appropriate antibodies for $15 \mathrm{~min}$ on ice, washed and then resuspended in FACS buffer.

For intracellular staining, cells were prestained for surface markers, fixed and permeabilized using either the Fixation/ Permeabilization Solution Kit (BD Biosciences) or the Foxp3/ Transcription Factor Staining Buffer Set (eBioscience) according to the manufacturer's instructions and then incubated with the appropriate antibodies for $30 \mathrm{~min}$ at room temperature. The cells were then washed and resuspended in FACS buffer before analysis.

All flow cytometry data were acquired with a MACSQuant ${ }^{\circledR}$ analyzer (Miltenyi Biotech), a Gallios flow cytometer (Beckman Coulter, Krefeld, Germany) or a BD LSRFortessa ${ }^{\mathrm{TM}} \mathrm{X}-20$ cell analyzer (BD Biosciences) and then analyzed using FlowJo software (version 10.2, TreeStar, Ashland, OR). During FACS analyses, all gatings were performed on live cells (determined by exclusion of the dye 7-AAD).
$\mathrm{CD} 34^{+} \mathrm{CD} 38^{+}$cells, hematopoietic stem cells, MLPs and MPPs were sorted from $\mathrm{CB} \mathrm{CD} 34^{+} \mathrm{HSPCs}$, and $\mathrm{CD} 34^{+} \mathrm{CD}^{+}$and $\mathrm{CD} 34^{-} \mathrm{CD}^{+}$cells were sorted after 7 days of culture on DL-4 in the presence or absence of TNFa (to exclude $\mathrm{CD}_{3} 4^{-} \mathrm{CD}^{-}$and $\mathrm{CD} 34^{+} \mathrm{CD}^{-}$cells from subsequent analyses). A FACSAria II SORP cell sorter (BD Biosciences) in the four-way high purity mode was used for this sorting.

Apoptosis assay

Cells harvested from 7-day DL-4 HSPC cultures in the presence or absence of TNFa were incubated with antibodies against CD34 and CD7 on ice for $15 \mathrm{~min}$. The cells were then washed and resuspended in binding buffer. Next, the cells were incubated with annexin V-PE (BD Biosciences) and 7AAD (BD Biosciences) in the dark at room temperature for $15 \mathrm{~min}$ and analyzed (using FACS) within an hour.

\section{Cell proliferation assay}

CD34 ${ }^{+}$HSPCs from CB or mPB were labeled with CFSE using a CellTrace $^{\text {TM }}$ CFSE kit (Life Technologies) according to the manufacturer's instructions. The labeled cells were then cultured in the DL-4 culture system in the presence or absence of TNFa. The CFSE labeling intensity was measured daily from day 3 to day 7 after surface staining with antibodies against CD34 and CD7.

\section{Cell cycle assay}

Cells harvested from 7-day DL-4 HSPC cultures in the presence or absence of TNFa were fixed and permeabilized (using the PerFixnc Kit (Beckman Coulter, Brea, CA)) at room temperature for 15 min after surface staining with antibodies against human CD34 and CD7. The cells were then stained with Hoechst 33342 (Life Technologies) and an anti-Ki67-PECy7 antibody (BD Biosciences) at room temperature for $15 \mathrm{~min}$.

\section{NFKB activation assay}

$\mathrm{mPB} \mathrm{CD} 34^{+} \mathrm{HSPCs}$ were seeded in DL-4- and RetroNectin-coated wells of a 96-well plate. After overnight culture, $100 \mathrm{ng} / \mathrm{ml} \mathrm{TNFa}$ was added, and the cells were fixed with Fix Buffer 1 (BD Biosciences) after $15 \mathrm{~min}, 30 \mathrm{~min}, 60 \mathrm{~min}, 24 \mathrm{~h}$ or $48 \mathrm{~h}$ of TNFa treatment according to the manufacturer's instructions. After fixation, the cells were then permeabilized with Perm Buffer III (BD Biosciences) according to the manufacturer's instructions. Then, they were stained with an anti-human NFkB p65 (pS529) antibody for $3 \mathrm{~h}$ at room temperature. The stained cells were then washed and resuspended in FACS buffer for data acquisition on a Gallios flow cytometer (Beckman Coulter).

\section{RNA sequencing}

RNA-seq was performed on FACS-sorted $\mathrm{CD} 34^{+} \mathrm{CD}^{+}$and $\mathrm{CD}_{3} 4^{-} \mathrm{CD} 7^{+}$progenitors on day 7 of $\mathrm{DL}-4$ culture. After measurement of the RNA integrity number and removal of ribosomal RNA (using InDA-C technology, NuGEN, CA), RNA-seq libraries were generated with an Ovation RNA-seq kit (NuGEN). Library fragment size was measured with a fragment analyzer (AATI, Agilent, CA). Libraries were sequenced using a HiSeq 2500 system (Illumina, CA).

Bioinformatic analysis of RNA-seq data

RNA reads were demultiplexed into FASTQ files, mapped to the ENSEMBL Human (hg19) reference database (using HISAT2), and then counted using featureCounts from the subread package in R. Read counts were normalized, and the subsets of progenitors induced in the presence or absence of TNFa were compared using three independent, complementary methods: DEseq2, EdgeR, and LimmaVoom. The results produced by each method were compared, grouped, and plotted as Venn diagrams. The results were filtered with the thresholds $p \leq 0.05$ and fold change >1.2. Functional data were obtained by IPA (Qiagen) and GSEA. Heat 
maps were generated using the Cluster and Tree Conversion (ctc) $\mathrm{R}$ package and imaged using Java TreeView software (version 1.1; https://sourceforge.net/). Principal component analysis was performed with the rgl R package.

T-cell receptor rearrangement analysis

T-cell receptor $\delta, \gamma$ and $\beta$ rearrangement analysis was performed by multiplex PCR followed by GeneScan analysis as described previously. ${ }^{30}$

\section{Vector copy number analysis}

The vector copy number was determined using a Droplet Digital PCR (ddPCR) system (Bio-Rad, Hercules, CA, USA) with specific primers and probes for HIV and albumin sequences.

\section{In vitro T-cell differentiation assay}

The in vitro T-lymphoid potential of HTLPs or transduced HTLPs was assessed by using an OP9-hDL-1 coculture system, as described previously. ${ }^{16} \mathrm{CD} 7^{+}$HTLPs or transduced HTLPs generated in 7-day DL-4 cultures of CB or mPB HSPCs in the presence or absence TNFa were cocultured on OP9-hDL1 stromal cells for 4 weeks. Every week, a quarter of the cultured cells was analyzed (using FACS) for the presence of $\mathrm{CD}^{+}{ }^{+} \mathrm{CD} 8^{+}$and TCRaß- or TCR $\gamma \delta$ expressing $\mathrm{CD}^{+} \mathrm{T}$ cells; three-quarters of the cells were reseeded on fresh OP9-hDL1 cells.

Adoptive transfer of in vitro-generated HTLPs into newborn NSG mice

A total of $5 \times 10^{5} \mathrm{CD}^{+}$HTLPs or transduced HTLPs generated in 7day DL-4 cultures of CB or MPB HSPCs in the presence or absence of TNFa were intrahepatically transplanted into newborn NSG mice (age: 1 and 4 days). Four weeks after transplantation, the thymus was analyzed (using flow cytometry) for human cell engraftment and thymopoiesis. At this time point, human cells were undetectable in the other hematopoietic organs. The study protocol was approved by the French Ministry of Higher Education and Research (reference: APAFIS 2010-2015090411495178v4, dated November 2nd, 2015).

Statistical analysis

The results of apoptosis experiments were analyzed using the Mann-Whitney rank-sum test. All other data were analyzed with one-way or one-way repeated-measures (RM) analysis of variance (ANOVA) or a paired or an unpaired two-tailed $t$ test. The data were plotted as the mean \pm SEM using GraphPad Prism software. The threshold for statistical significance was set to $p<0.05$. All statistical analyses were performed using either SigmaStat software (version 3.5, Jandel Scientific, San Rafael, CA) or GraphPad Prism software (version 8.4.3, San Diego, CA).

\section{RESULTS}

TNFa increases the production of DL-4-induced $\mathrm{CD}_{3} 4^{-} \mathrm{CD} 7^{+}$ progenitors

First, we screened PhAA, SR1, TNFa, UM171 and UM729 for their ability to improve the cell expansion and yields of HTLPs by culturing $\mathrm{CB}$ or $\mathrm{mPB} C D 34^{+} \mathrm{HSPCs}$ with each of these molecules in a DL-4/RetroNectin ${ }^{\circledR}$ culture system (referred to henceforth as "HTLP culture") $)^{20,21}$ for 7 days. We observed that the addition of TNFa gave rise to the highest frequency $(>90 \%)$ and number (17fold and 25 -fold increases for the $\mathrm{CB}$ and $\mathrm{mPB}$, respectively, with respect to those obtained from negative control culture without any small molecules) of $\mathrm{CD}^{+}$HTLPs among all the molecules tested (Supplementary Fig. S1A and B). Therefore, we selected TNFa to further explore its potential to improve the HTLP yield of DL-4 cultures of CB or mPB HSPCs. In the absence of TNFa, and as expected on the basis of our previous results, the day-7 cell product contained a mixture of $\mathrm{CD}_{3} 4^{-} \mathrm{CD} 7^{-}$progenitors (i.e., myeloid progenitors $\left.{ }^{20}\right), \mathrm{CD}_{3} 4^{+} \mathrm{CD}^{-}$cells, and $\mathrm{CD} 34^{+} \mathrm{CD} 7^{+}$early and $\mathrm{CD} 34^{-} \mathrm{CD} 7^{+}$late T-cell progenitors (Fig. 1A (upper panels) and B). In the presence of TNFa, the day-7 cell product was much more homogeneous (1.85-fold increase for the CB and 3.2-fold increase for the $\mathrm{mPB}$ ), consisting mostly of $\mathrm{CD} 34^{-} \mathrm{CD} 7^{+}$late $\mathrm{T}$-cell progenitors (mean \pm standard error of the mean (SEM) frequencies of $86.74 \pm 2.40 \%$ and $71.42 \pm 5.84 \%$ for the $C B$ and $\mathrm{mPB}$, respectively, in the presence of TNFa vs. $46.58 \pm 3.06 \%$ and $22.36 \pm 3.88 \%$ in the absence of TNFa) (Fig. 1A (lower panels) and $B)$. Hence, the addition of TNFa was associated with an average 10 -fold increase in the $\mathrm{CD}^{+}{ }^{+}$HTLP yield for both CB HSPC cultures and $\mathrm{mPB}$ HSPC cultures (Fig. 1C). Interestingly, neither early $\mathrm{CD} 34^{+} \mathrm{CD}^{+}$progenitors nor late $\mathrm{CD} 34^{-} \mathrm{CD} 7^{+}$progenitors were observed in the 7-day TNFa-supplemented cultures without DL-4, suggesting that the effect of TNFa was dependent on DL-4 (Fig. 1D).

Daily CD34/CD7 phenotyping showed differentiation of $C B$ and $\mathrm{mPB}$ HSPCs into early $\mathrm{CD} 34^{+} \mathrm{CD} 7^{+}$progenitors but not differentiation into late $\mathrm{CD}_{3} 4^{-} \mathrm{CD} 7^{+}$T-cell progenitors until day 4 . In the presence of TNFa, however, higher levels of differentiation into late $\mathrm{CD}_{34}{ }^{-} \mathrm{CD} 7^{+} \mathrm{T}$-cell progenitors were observed from day 5 onwards, with a frequency of nearly $90 \%$ at day 7 (Supplementary Fig. S2A).

Regardless of TNFa exposure, HTLPs barely expressed CD5 or CD1a (Supplementary Fig. S2B) or harbored any detectable T-cell receptor (TCR) $\delta, \gamma$ and $\beta$ rearrangements (Supplementary Fig. S3A and B). Importantly, CD7 ${ }^{+}$HTLPs expressed GATA3, BCL11B (two key transcriptional regulators of T-cell differentiation $\left.{ }^{31}\right)$, and CD3E (Fig. 1E). Notably, the expression level of CD3E was significantly higher in TNFa-exposed HTLPs than in unexposed HTLPs. However, the expression levels of BCL11b and GATA3 showed no significant differences between TNFa-exposed and nonexposed HTLPs (Fig. 1E).

Next, to determine which HSPC subset responded to TNFa treatment, we used fluorescence-activated cell sorting (FACS) to isolate $\mathrm{CD}_{34}{ }^{+} \mathrm{CD} 38^{+}$cells, HSCs, multilymphoid progenitors (MLPs) and multipotent progenitors (MPPs) from CB CD34 ${ }^{+}$cells (Supplementary Fig. S3C) and cultured the cells in the presence or absence of TNFa. The results demonstrated that both the frequencies and absolute counts of day- $7 \mathrm{CD}^{+}$progenitor cells (i.e., HTLPs) obtained from these subpopulations were higher in the presence of TNFa than in its absence (Fig. 1F-H). Interestingly, MLPs and $\mathrm{CD}_{3} 4^{+} \mathrm{CD} 38^{+}$cells appeared to have the greatest potential for generating late T-cell progenitors $\left(C D 34^{-} C D 7^{+}\right)$in the presence of TNFa during the culture period of 7 days.

Taken together, these data show that TNFa accelerates and

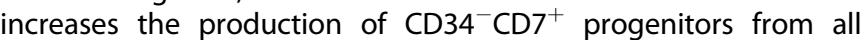
HSPC cell subsets without any restriction to a specific progenitor subset.

TNFa specifically promotes the survival and proliferation of $C D 7^{+}$ progenitors

To explore the mechanism underlying the TNFa-associated increase in the generation of $\mathrm{CD}^{-} 4^{-} \mathrm{CD} 7^{+}$progenitors, we assessed the apoptosis and proliferation of HTLPs in HTLP cultures. Staining with Annexin V and 7-aminoactinomycin D (7AAD) showed that compared with no exposure, TNFa exposure was associated with a significantly lower level of apoptosis among $\mathrm{CD}^{+}$progenitors in HTLP cultures of CB and mPB HSPCs (Fig. 2A). In contrast, the level of apoptosis among $\mathrm{CD}^{-}$cells was slightly but not significantly lower in both CB HSPC cultures and mPB HSPC cultures in the presence of TNFa (Fig. 2B). Moreover, flow cytometric analyses for the expression of $\mathrm{Bcl}-2$ and $\mathrm{Mcl}-1$ (antiapoptotic proteins ${ }^{32,33}$ ) revealed that although all $\mathrm{CD}^{+}$ progenitors expressed $\mathrm{BCl}-2$ in both culture conditions (with or without TNFa), the addition of TNFa was associated with an increase in the proportion of $\mathrm{Mcl}$-1-expressing cells among the $\mathrm{CD}^{+}$progenitors (Supplementary Fig. S4A and B). Importantly, 


\section{A}

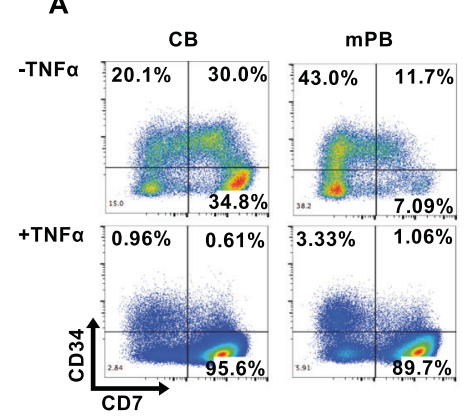

B

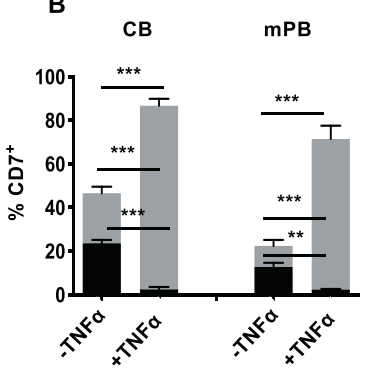

C

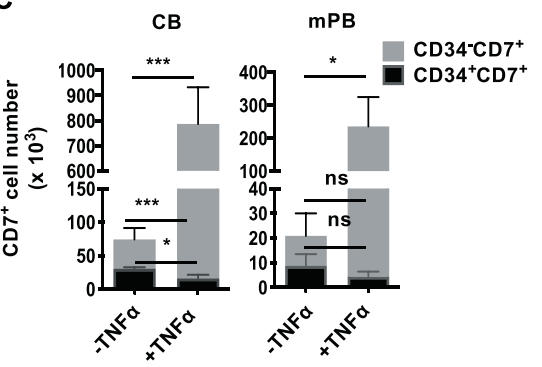

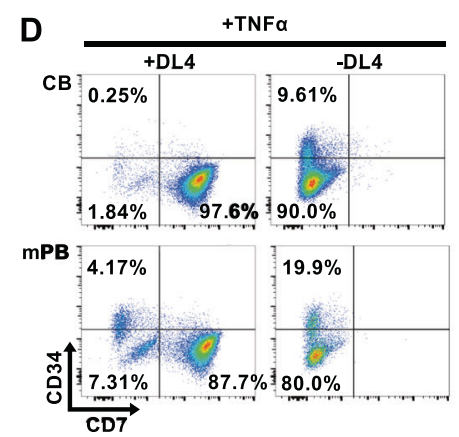
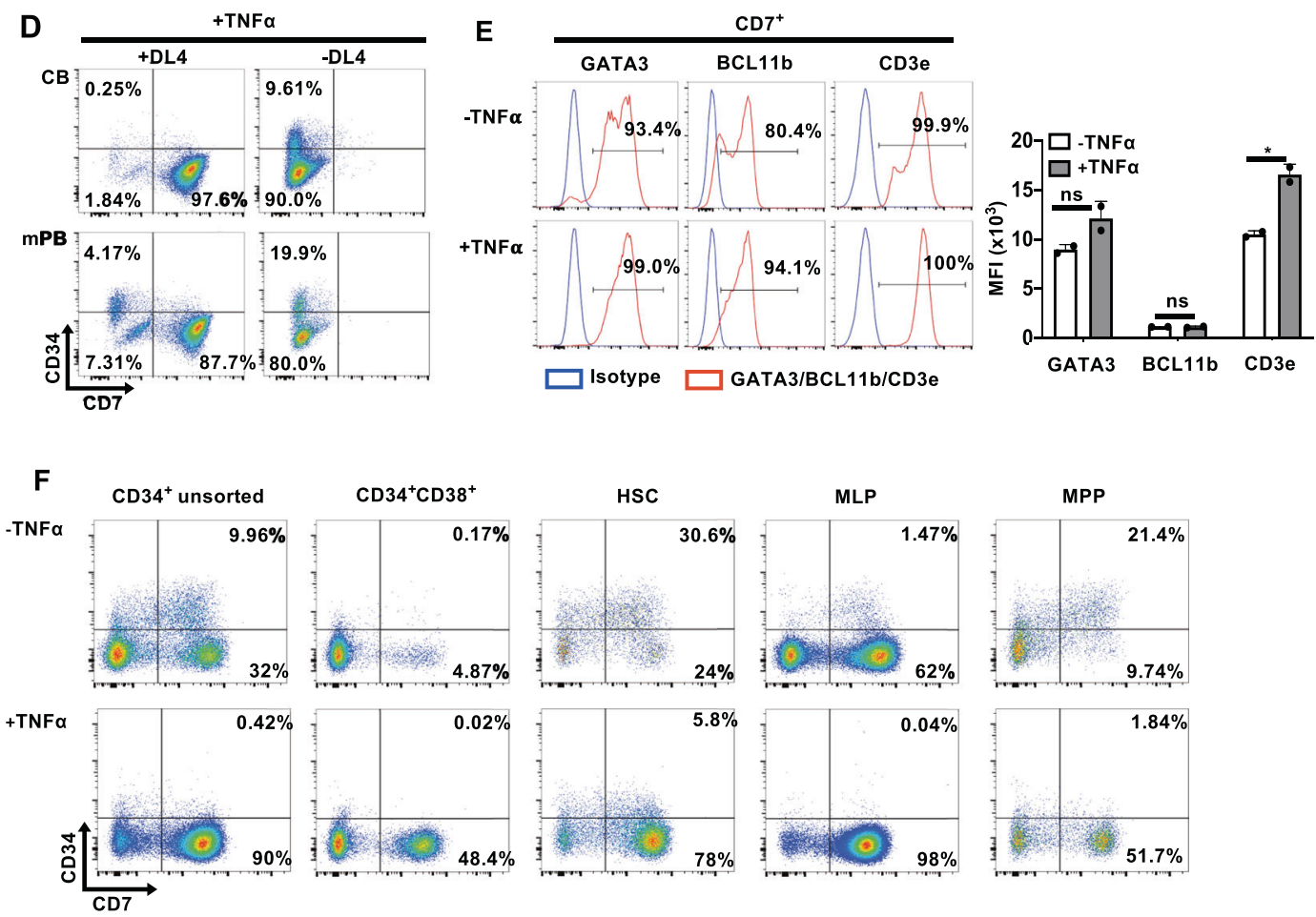

G

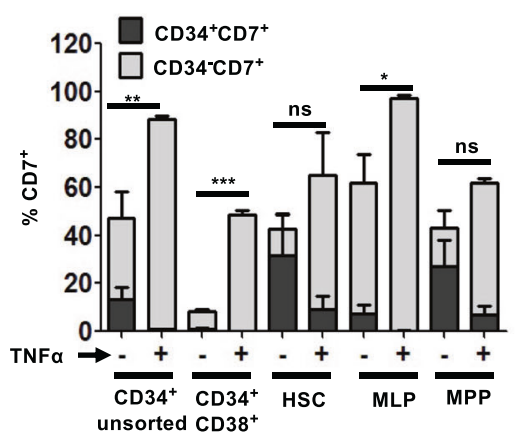

H

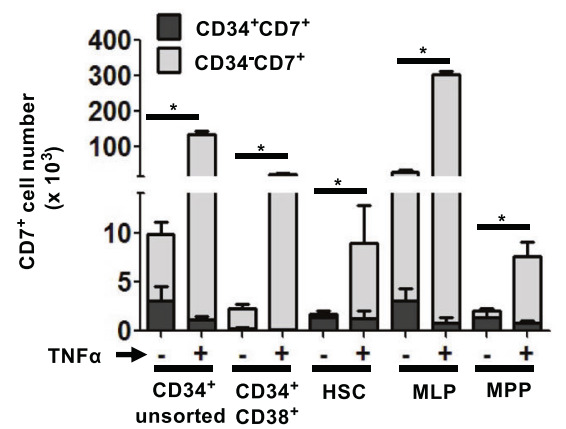

Fig. 1 TNF $\alpha$ promotes the in vitro production of $C D 7^{+}$HTLPs from DL-4 cultures of CB or mPB HSPCs. A A representative FACS plot of the phenotype of DL-4-cultured CB or mPB HSPCs after 7 days of culture in the presence $(100 \mathrm{ng} / \mathrm{ml})$ or absence of TNF $\alpha$. Graphs showing the mean frequencies $(\mathbf{B})$ and numbers $(\mathbf{C})$ of $C D 34^{+} \mathrm{CD}^{+}$progenitors (in black) and $\mathrm{CD} 34^{-} \mathrm{CD} 7^{+}$progenitors (in light gray) after 7 days of culture in the presence $(100 \mathrm{ng} / \mathrm{ml})$ or absence of TNF $\alpha$ (mean \pm SEM, $n=7)$. The $p$ values were calculated by one-way RM ANOVA: ${ }^{*} p \leq 0.05$; ${ }^{* *} p \leq 0.01$; ${ }^{* * *} p \leq 0.001$. D Representative FACS plot of the phenotype of CB or mPB HSPC cultures with or without DL-4 in the presence of TNF $\alpha$. $\mathbf{E}$ Representative FACS histograms for the expression of the T-cell commitment markers GATA3, BCL11b, and CD3 $\varepsilon$ on day-7 CD7 ${ }^{+}$HTLPs (left panel) and their corresponding median fluorescence intensity (MFI) values (right panel) (mean $\pm \mathrm{SEM}, n=2$ ). The $p$ values were calculated using an unpaired two-tailed $t$ test: ${ }^{*} p \leq 0.05$. F Representative flow cytometry plots of CB-derived HSPC subpopulations grown for 7 days in a DL-4 culture system in the presence or absence of TNF $\alpha$. G Graphs showing the frequencies and $\mathbf{H}$ absolute numbers of CD34 ${ }^{+} \mathrm{CD} 7^{+}$and $\mathrm{CD} 34^{-} \mathrm{CD}^{+}$cells (mean $\pm \mathrm{SEM}, n=3$ ). The $p$ values were calculated by one-way ANOVA: ${ }^{*} p \leq 0.05 ;{ }^{* *} p \leq 0.01 ;{ }^{* * *} p \leq 0.001$ 
A

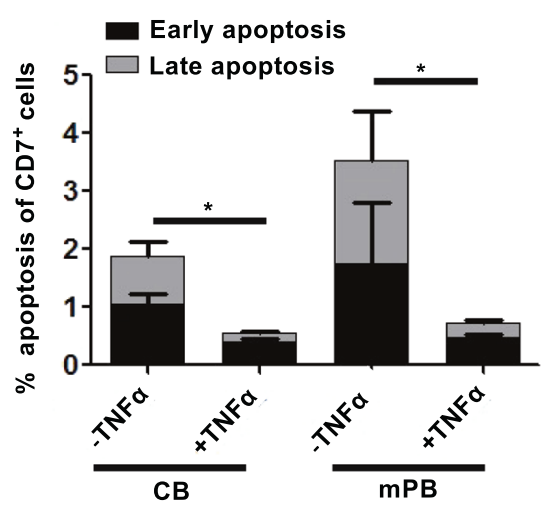

C

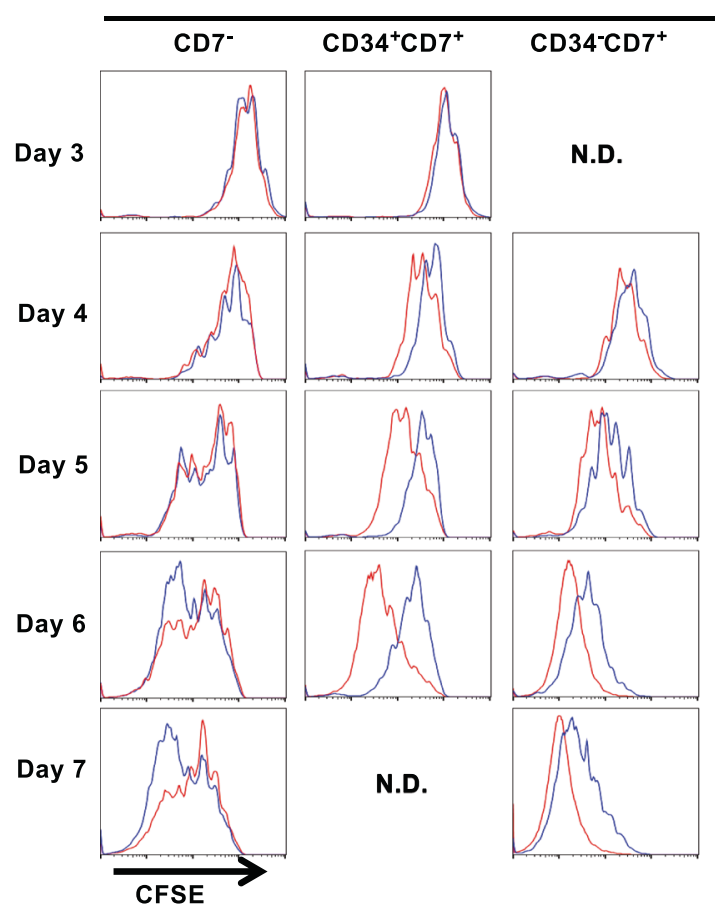

B

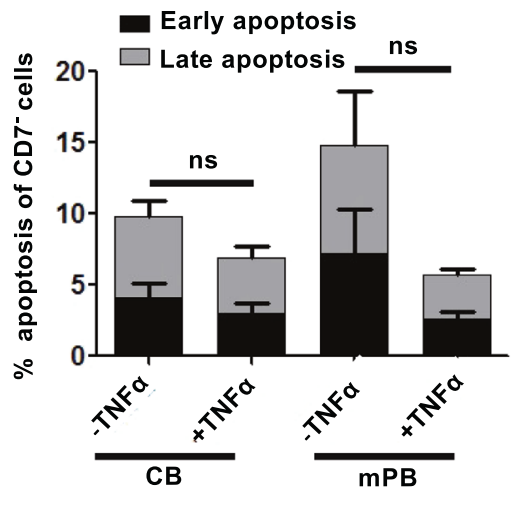

mPB

\begin{tabular}{|c|c|c|}
\hline CD7'- & $\mathrm{CD}_{3} 4^{+} \mathrm{CD} 7^{+}$ & CD34 ${ }^{\circ} \mathrm{CD} 7^{+}$ \\
\hline
\end{tabular}

N.D. $\square$ - TNF $\alpha$
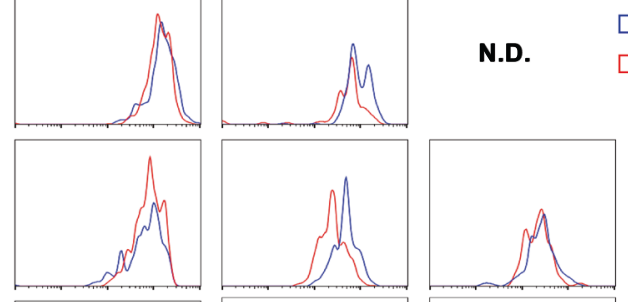
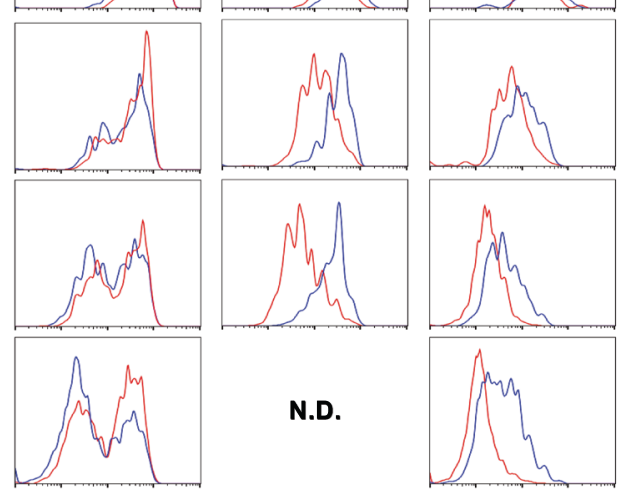

N.D.
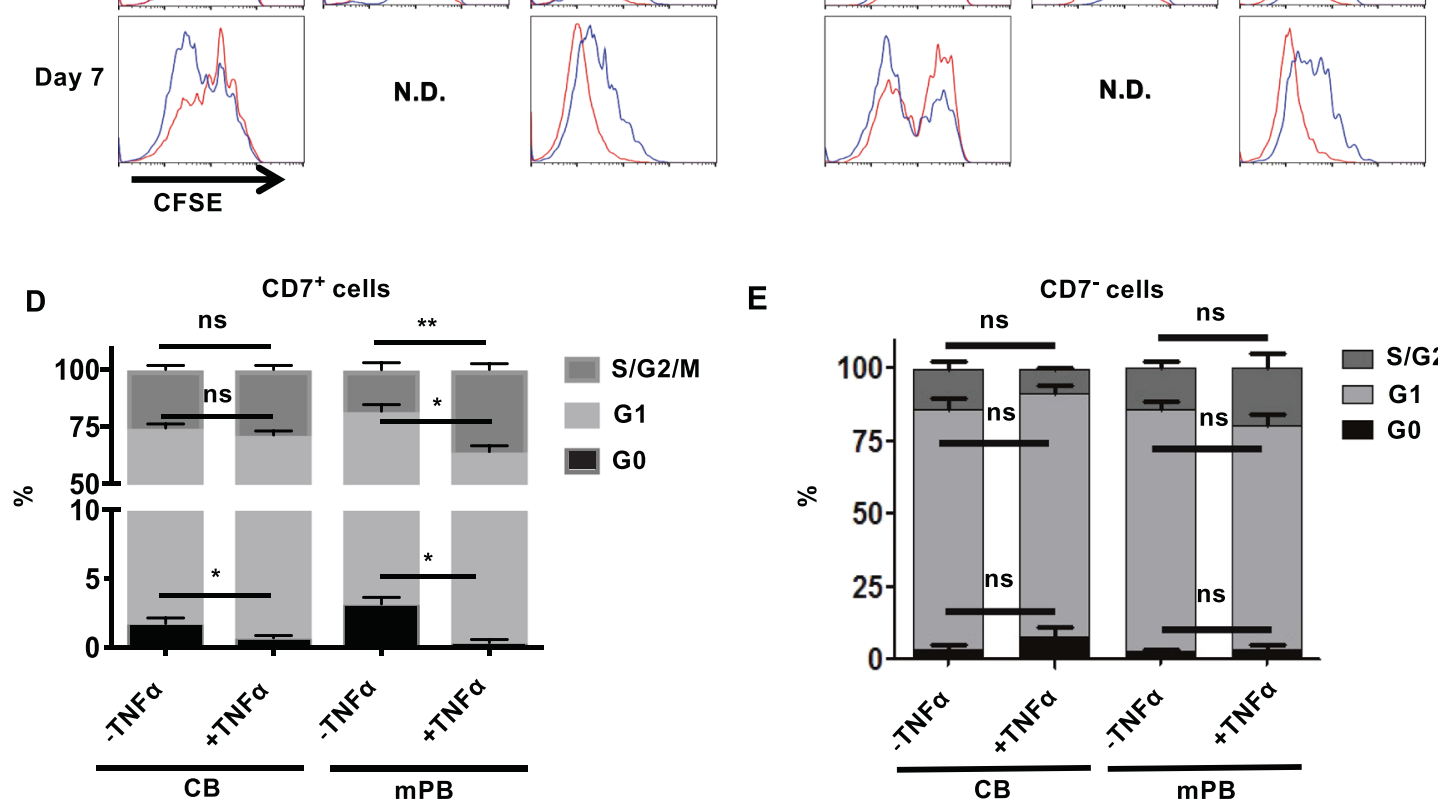

E

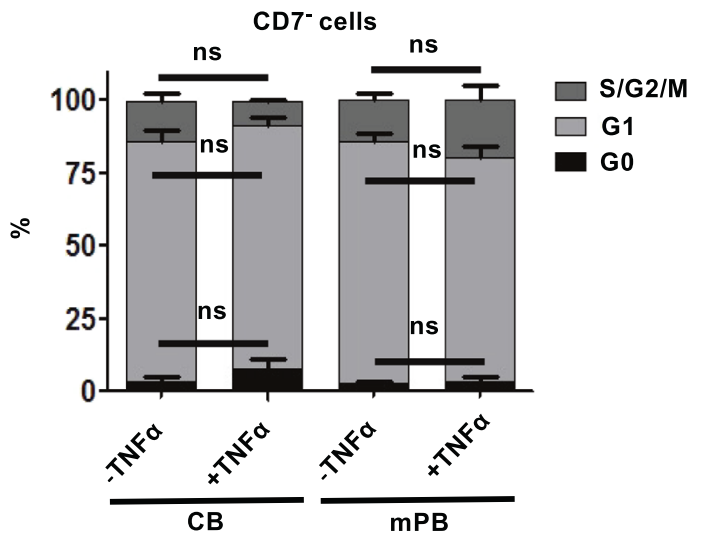

Fig. 2 Enhanced cell survival and proliferation of $C D 7^{+}$HTLPs in the presence of TNF $\alpha$ in DL-4 cultures of CB or $m P B$ HSPCs. A,B The level of apoptosis, analyzed by staining with Annexin- $V$ and 7-AAD (early and late apoptosis correspond to $A n n e x i n-V^{+} 7-A^{-} D^{-}$and $A n n e x i n-V^{+} 7-$ $A A D^{+}$phenotypes, respectively), among $C D 7^{+}$HTLPs $(\mathbf{A})$ and $C D 7^{-}$cells (B) after 7 days of DL-4 culture in the presence or absence of TNF $\alpha$ (mean $\pm \mathrm{SEM}, n=4$ ). $P$ values were calculated using the Mann-Whitney rank-sum test; ${ }^{*} p \leq 0.05$. C Assessment of cell proliferation (based on CFSE dilution) from day 3 to day 7 in DL-4 cultures in the presence or absence of TNF $\alpha$. CD34 ${ }^{+}$cells were labeled with CFSE prior to DL-4 culture. The frequencies of quiescent (G0) cells and cells in the G1 or S/G2/M phases of the cell cycle among CD7 ${ }^{+} \mathrm{HTLPs}^{(D)}$ and CD7 ${ }^{-}$cells (E) after 7 days of DL-4 culture in the presence or absence of TNF $\alpha$ (mean $\pm \mathrm{SEM}, n=3$ ). The $p$ values were calculated by one-way RM ANOVA: ${ }^{*} p \leq$ $0.05 ;{ }^{*} p \leq 0.01$ 
1668

the levels of expression of both $\mathrm{Bcl}-2$ and $\mathrm{Mcl}-1$ in $\mathrm{CD}^{+}$ progenitors were significantly higher in cultures with TNFa (Supplementary Fig. S4A and B). These results suggested that TNFa might increase the survival of $\mathrm{CD}^{+}$progenitors by upregulating $\mathrm{BCl}-2$ and $\mathrm{Mcl}-1$ expression and thus protecting the cells from apoptosis.

The results of a cell proliferation assay (based on the dilution of carboxyfluorescein succinimidyl ester (CFSE) labeling) showed that although the $\mathrm{CD7}^{-}$cell proliferation rate was least affected by TNFa exposure, the proliferation rates of both $\mathrm{CD} 34^{+} \mathrm{CD}^{+} \mathrm{T}$-cell progenitors and $\mathrm{CD} 34^{-} \mathrm{CD}^{+}{ }^{-}$-cell progenitors were increased in the presence of TNFa (starting from day 4 and day 5 of HTLP culture, respectively; Fig. 2C). These observations were in line with the results of a cell cycle assay (with Hoechst 33342 and anti-Ki67 antibody staining) performed with HTLP cultures; a higher proportion of S/G2/M-phase cells and a lower proportion of G0phase cells were observed among $\mathrm{CD}^{+}$cells (especially for $\mathrm{mPB}$ cultures) in the presence of TNFa, while the proportions were similar for $\mathrm{CD}^{-}$cells (Fig. 2D,E). Taken together, these data demonstrate that TNFa specifically (i) increases the survival of $\mathrm{CD}^{+}$progenitors by decreasing apoptosis and (ii) enhances the proliferation of $\mathrm{CD}^{+}$progenitors by increasing cell cycling (possibly through the NFkB signaling pathway ${ }^{34}$ ).

Transcriptomic profiles of CB- and mPB-derived HTLPs and the role of NFKB signaling in TNFa-induced enhanced HTLP generation

To explore the effect of TNFa on the transcriptomic profile of day7 HTLPs, we sequenced and compared RNA from late $\left(\mathrm{CD} 34^{-} \mathrm{CD}^{+}\right)$progenitors produced in TNFa-supplemented HTLP cultures and from early $\left(\mathrm{CD} 34^{+} \mathrm{CD}^{+}\right)$and late progenitors produced in the absence of TNFa. Unfortunately, the numbers of late progenitors obtained with MPB HSPCs in the absence of TNFa and the numbers of early progenitors obtained in the presence of TNFa were very low, which prevented us from assessing gene expression levels. Principal component analysis of gene expression showed a clear difference in the clustering of early $\left(\mathrm{CD} 34^{+} \mathrm{CD}^{+}\right)$vs. late $\left(\mathrm{CD} 34^{-} \mathrm{CD}^{+}\right)$progenitors under all conditions (Fig. 3A). Notably, the late $\left(\mathrm{CD} 34^{-} \mathrm{CD} 7^{+}\right)$progenitors derived from TNFa-supplemented or nonsupplemented CB HTLP cultures were found to be closely clustered, suggesting that TNFa treatment did not alter the progenitor transcriptomic profile (Fig. 3A). Moreover, the clustering of TNFa-exposed mPB late progenitors and TNFa-exposed and nonexposed CB late progenitors indicated similar transcriptomic profiles, regardless of the cell source (Fig. 3A). When we performed gene set enrichment analysis (GSEA) of FACS-sorted CD7 ${ }^{+}$T-cell progenitors, we observed a clear enrichment in cell cycle pathways in the presence of TNFa ( $p$ $<0.01$; Fig. 3B-D). This agreed with the observed effect of TNFa on the cell cycle, as described above (Fig. 2D). Ingenuity pathway analysis (IPA) of the RNA-sequencing (RNA-seq) results predicted that the NFKB signaling pathway must be activated by TNFa to explain the difference in the gene expression profiles (Fig. 4A). This result is in line with literature reports showing that TNFa is one of the main activators of the NFKB signaling pathway. ${ }^{35}$

We showed that tumor necrosis factor receptors (TNFRs) I and II were expressed in HSPCs (Supplementary Fig. S5A). Interestingly, TNFa significantly and specifically increased the expression of both TNFR I and TNFR II in CD7 ${ }^{+}$HTLPs (Supplementary Fig. S5B and $C$, left panels) compared to $\mathrm{CD}^{-}$cells (Supplementary Fig. S5B and C, right panels). Next, we explored the activation of NFKB signaling by TNFa in HTLP cultures. As shown in Fig. 4B, there was a low basal level of phosphorylated NFKB in HTLPs without TNFa treatment. However, TNFa tremendously increased NFKB signaling after $15 \mathrm{~min}$. Between 15 and $60 \mathrm{~min}$, the level of phosphorylated NFKB decreased slowly and then remained stable up to $48 \mathrm{~h}$ at a level higher than the basal level.

To further confirm that the TNFa-mediated effect on $\mathrm{CD}^{+}$cells was - at least partly - a consequence of the activation of NFKB signaling, mPB HSPCs were cultured under HTLP conditions in the presence or absence of TNFa or in the presence of both TNFa and piceatannol (an NFKB inhibitor). We observed that the addition of piceatannol abolished the TNFa-induced effects on both the frequency and yield of $\mathrm{CD7}^{+}$HTLPs (with decreases of 2.4- and 35fold, respectively, Fig. 4C-E), showing the importance of NFKB signaling in the TNFa-induced effect. Interestingly, the inhibition of NFKB signaling by piceatannol significantly reduced the levels of TNFR I and II expression in CD7 ${ }^{+}$HTLPs (Supplementary Fig. S5B and $C$, left panels), suggesting a role for NFKB signaling in this process.

Taken together, these data suggested that TNFa increased the generation of $\mathrm{CD}^{+}$HTLPs in HTLP cultures by activating NFKB signaling.

\section{Enhanced T-cell potential of TNFa-exposed HTLPs}

We next tested the in vitro T-cell differentiation potential of $\mathrm{CD}^{+}$ HTLPs by performing cocultures with human delta-like-1 (hDL-1)expressing bone marrow (BM) stromal (OP9-hDL1) cells. The T-cell differentiation status was analyzed weekly during the cocultures. $\mathrm{CD}^{+} \mathrm{CD}^{+}$double-positive (DP) cells appeared at week 1 in the CB HTLP cocultures (whether treated with TNFa or not) and in the TNFa-treated $\mathrm{mPB}$ HTLP coculture and at week 2 in the nontreated mPB HTLP coculture (Fig. 5A and Supplementary Fig. S6A). Moreover, $\mathrm{CD}^{+}$cells (expressing $\gamma \delta$ or $a \beta$ TCRs) were detected earlier in TNFa-treated CB and MPB HTLP cocultures than in nontreated HTLP cocultures (Fig. 5B and Supplementary Fig. S6B). Importantly, TNFa-exposed CB and mPB HTLP cocultures gave rise to higher proportions of $\mathrm{DP}$ and $\mathrm{CD}^{+}$cells than nonexposed cultures (Fig. 5A, B and Supplementary Fig. S6A and B). These observations suggest that TNFa-treated $C B$ and MPB HTLPs differentiate more rapidly and efficiently into T cells. Importantly, the TCR repertoire (i.e., $\delta, \gamma$ and $\beta$ locus rearrangements) was polyclonal without any bias under all conditions (Fig. 5C).

The in vivo T-cell potential of TNFa-treated HTLPs was then tested by intrahepatic transplantation into nonirradiated neonatal NSG mice. Four weeks after transplantation, human (h)CD45 ${ }^{+}$cells colonized the thymus to a similarly high extent (>90\%) in all CB HTLP (whether treated with TNFa or not) recipients. However, the hCD45 $5^{+}$cell count was 2.4-fold higher for TNFa-treated CB HTLPs than for nontreated HTLPs (Fig. 5E and Supplementary Fig. S6C). The frequencies and numbers of $\mathrm{hCD} 45^{+}$cells were also higher for TNFa-treated mPB HTLPs (by factors of 2.1 and 39.4, respectively) than for nontreated HTLPs (Fig. 5F and Supplementary Fig. S6C). Active thymopoiesis (measured by the presence of human $\mathrm{CD}_{4} 5^{+} \mathrm{CD} 4^{+} \mathrm{CD} 8{ }^{+} \mathrm{DP}$ cells) was observed under all conditions (Fig. 5G,H and Supplementary Fig. S6D). In CB HTLP recipients, although the proportion of DP cells was similar, the number of DP cells was 2.5-fold higher for TNFa-treated HTLPs (Fig. 5G and Supplementary Fig. S6D). In recipients of mPB HTLPs, the frequencies and numbers of DP cells were greater for TNFatreated HTLPs (by factors of 2.8 and 134, respectively) than for untreated HTLPs (Fig. 5H and Supplementary Fig. S6D); this finding was consistent with the observed enlargement of the thymus (Fig. 5D). The recipients of TNFa-treated HTLPs, relative to untreated HTLP recipients, showed enhanced $\mathrm{CD}^{+}$cell frequencies (1.4- and 12.3-fold increases for CB and MPB HTLPs, respectively) and numbers (3- and 768-fold increases for $C B$ and mPB HTLPs, respectively) (Fig. 5I,J and Supplementary Fig. S6E). These results demonstrate the enhanced in vitro and in vivo T-cell potential of TNFa-treated HTLPs derived from CB or mPB HSPCs.

Efficient production of transduced genetically modified HTLPs from TNFa-supplemented HTLP cultures

To examine whether genetically modified transduced $\mathrm{CD} 7^{+} \mathrm{HTLPs}$ could be generated in TNFa-supplemented HTLP cultures, CB or mPB CD34 ${ }^{+}$HSPCs were preactivated, transduced or not (mock) with a vesicular stomatitis virus (VSV)-G pseudotyped lentiviral 
A

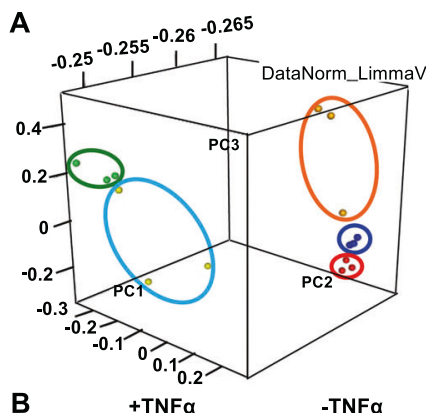

C

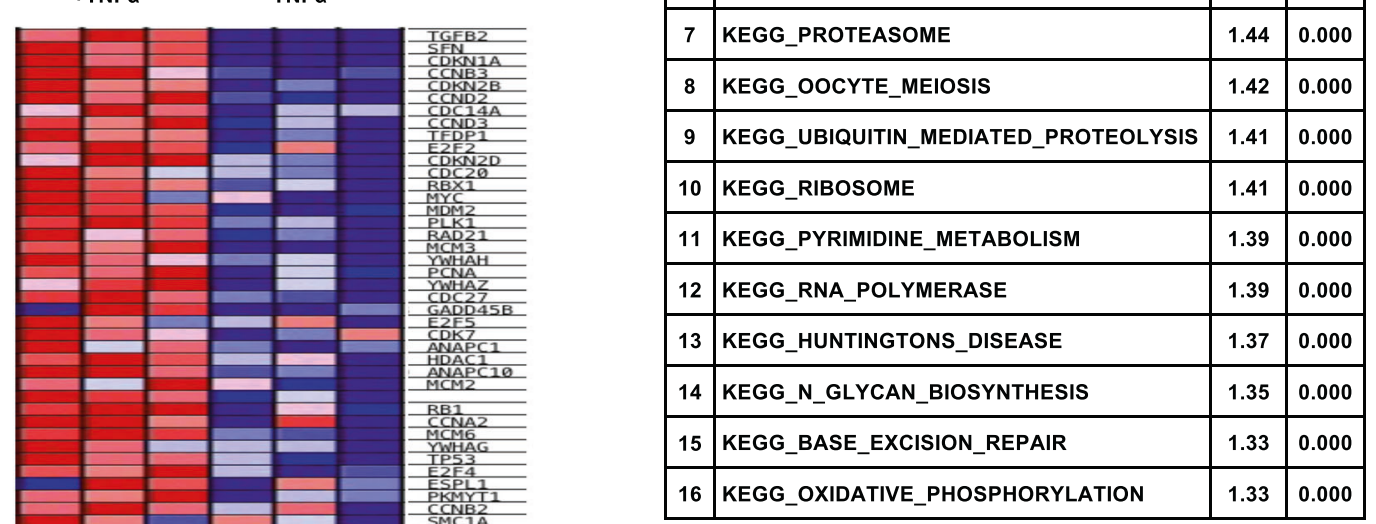

D
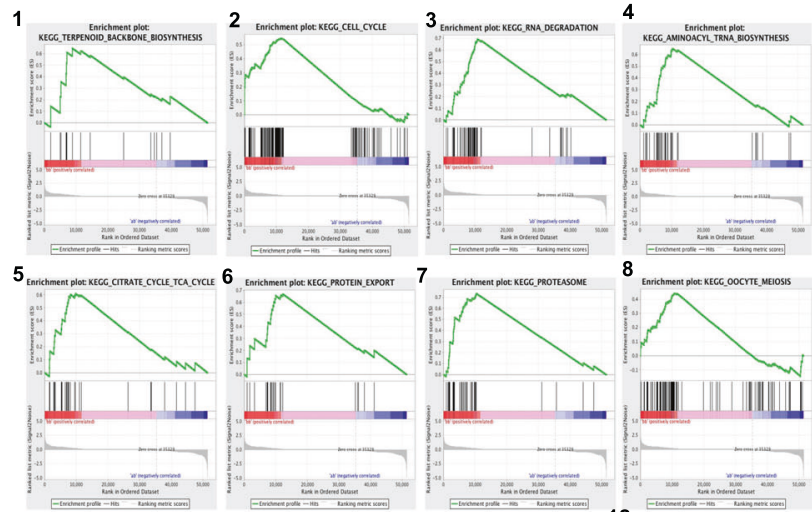

8
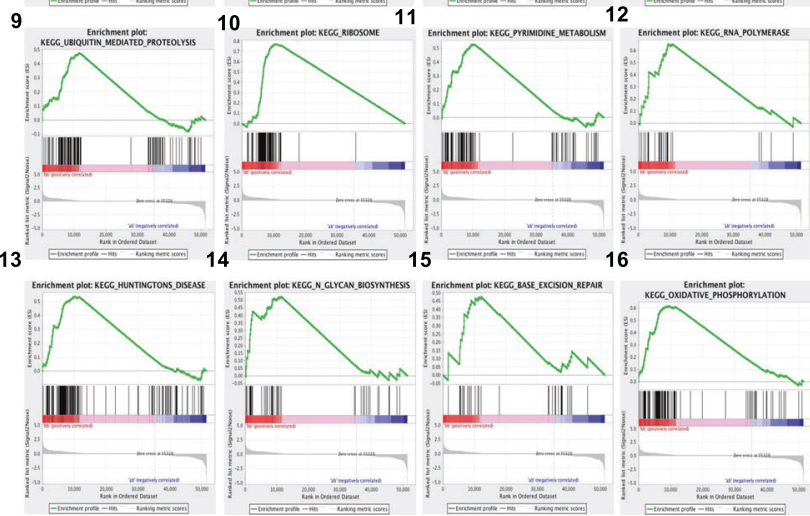

Fig. 3 Similar transcriptomic profiles of TNF $\alpha$-exposed and nonexposed CD34- $C D 7^{+}$late T-cell progenitors. A PCA after RNA sequencing of sorted $\mathrm{CB}$ or $\mathrm{mPB}$ HSPC-derived $\mathrm{CD} 34^{+} \mathrm{CD} 7^{+}$and $\mathrm{CD} 34^{-} \mathrm{CD} 7^{+}$progenitors after 7 days of DL- 4 culture. Each point represents a replicate sample. B A heat map representing the gene expression profile for the cell cycle pathway among $\mathrm{CD} 34^{-} \mathrm{CD} 7^{+}$progenitors generated from $\mathrm{CB}$ HSPCs. C, D GSEA of RNA-seq data obtained from CD $34^{-}$CD7 $7^{+}$cells generated in the presence or absence of TNF $\alpha$. C The 16 pathways (out of 20) with the highest normalized enrichment scores (all $p<0.01$ ) and $\mathbf{D}$ their corresponding GSEA plots, showing the enrichment profile 
A

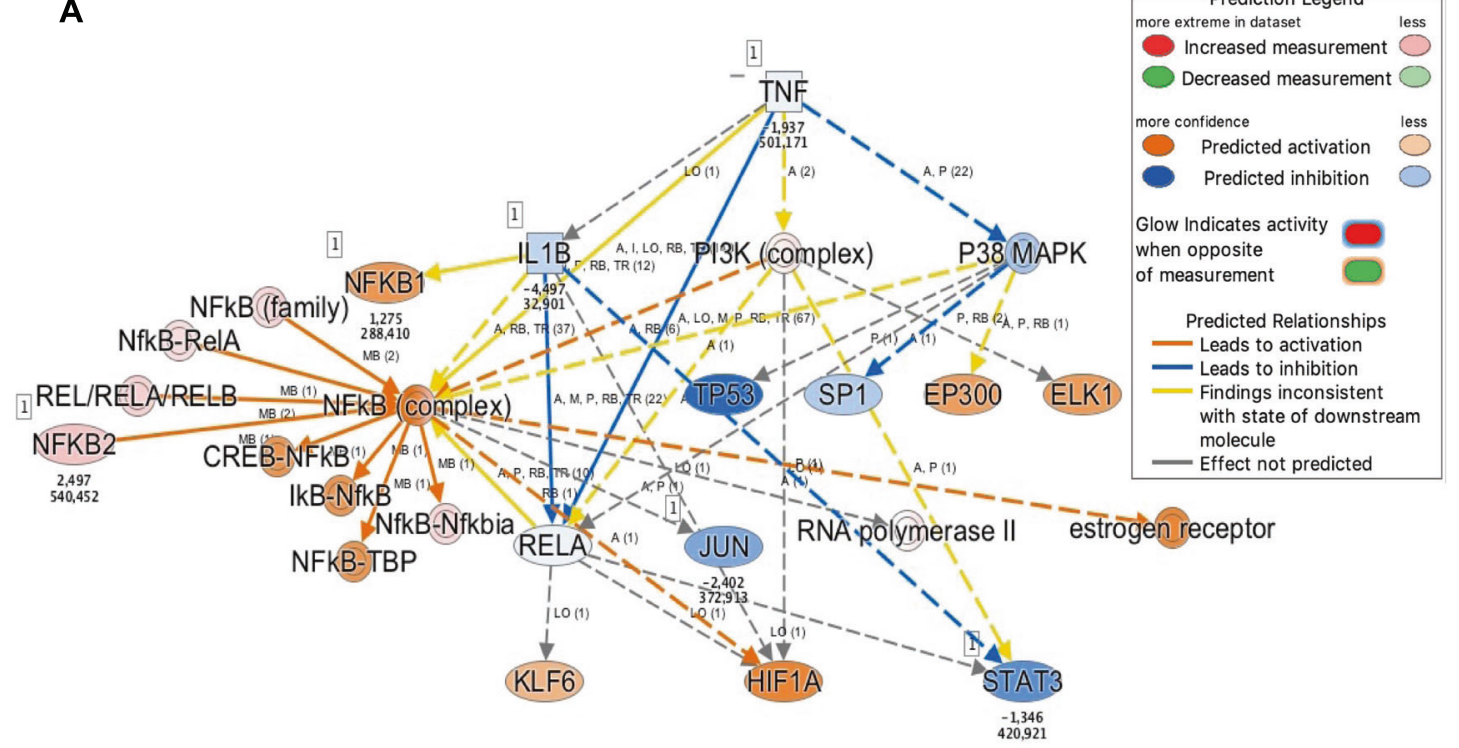

B

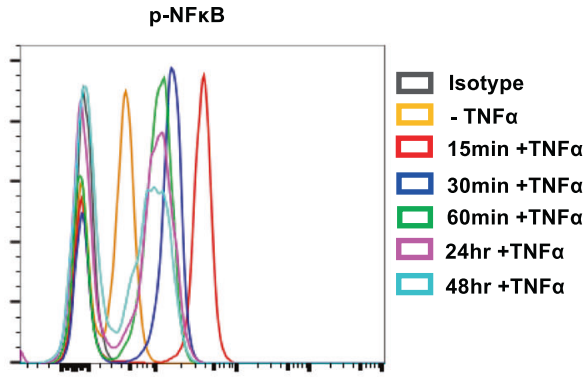

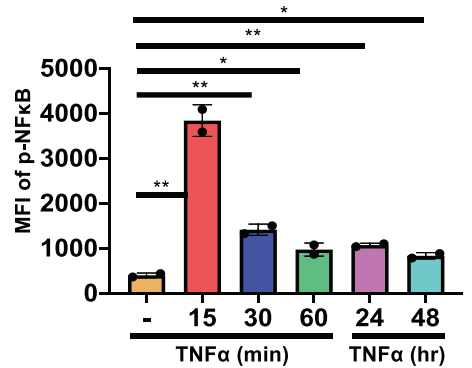

+TNF $\alpha /+$ Piceatannol

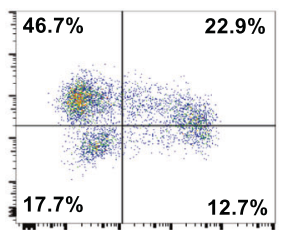

$2.7 \%$

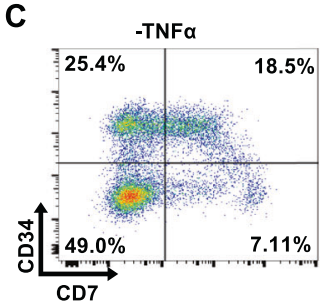

D

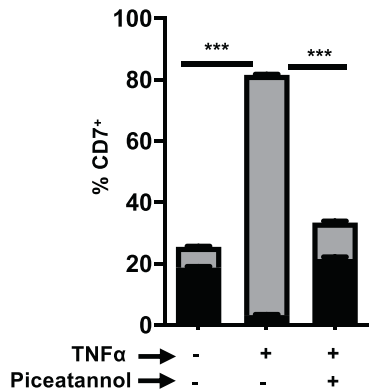

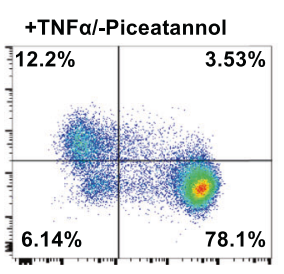

E

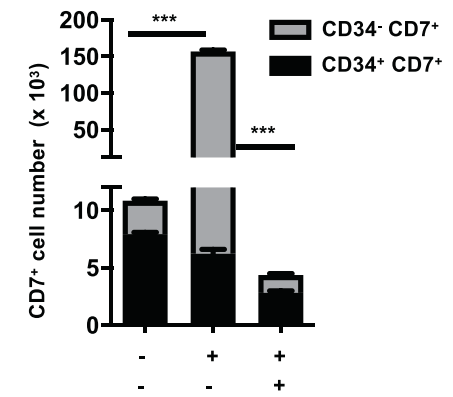

Fig. $4 \quad \mathrm{NF \kappa B}$ signaling mediated TNF $\alpha$-induced enhanced $\mathrm{CD7} 7^{+} \mathrm{HTLP}$ generation. A The predicted regulatory pathway network by IPA based on differential gene expression by $\mathrm{CD} 34^{-} \mathrm{CD} 7^{+}$cells generated in the presence or absence of TNF $\alpha$. IPA was performed after RNA sequencing of sorted $\mathrm{CB}$ or $\mathrm{mPB} \mathrm{HSPC}$-derived $\mathrm{CD} 34^{+} \mathrm{CD} 7^{+}$and $\mathrm{CD} 34^{-} \mathrm{CD} 7^{+}$progenitors after 7 days of DL-4 culture. B A representative FACS histogram showing the phosphorylation of NFKB (left panel) and corresponding MFIs (right panel) at the indicated time points after treatment with TNF $\alpha$ during HTLP culture (mean $\pm \mathrm{SEM}, n=2$ ). The $p$ values were calculated by an unpaired two-tailed $t$ test: ${ }^{*} p \leq 0.05 ;{ }^{* *} p \leq 0.01$. C A representative FACS plot of the phenotype of 7-day HTLP cultures of mPB HSPCs in the presence $(100 \mathrm{ng} / \mathrm{ml})$ or absence of TNF $\alpha$ or in the presence of TNF $\alpha$ and piceatannol $(25 \mu \mathrm{M})$ (an NFkB inhibitor). Graphs showing the mean frequencies (D) and numbers (E) of CD34 ${ }^{+} \mathrm{CD} 7^{+}$progenitors (in black) and $\mathrm{CD}_{3} 4^{-} \mathrm{CD}^{+}$progenitors (in light gray) after 7 days of HTLP culture of $\mathrm{mPB} \mathrm{HSPCs}$ in the presence $(100 \mathrm{ng} / \mathrm{ml})$ or absence of TNF $\alpha$ or in the presence of TNF $\alpha$ and piceatannol $(25 \mu \mathrm{M}$ ) (an NFkB inhibitor) (mean \pm SEM, $n=3$ ). The $p$ values were calculated by one-way ANOVA: $* * * 0 \leq 0.001$ 
A

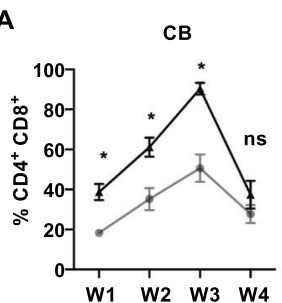

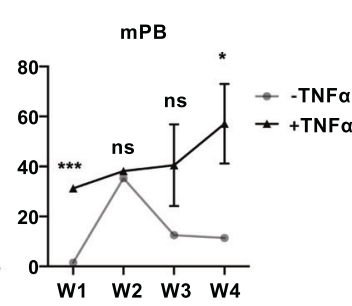

B $\quad \mathrm{CB}$

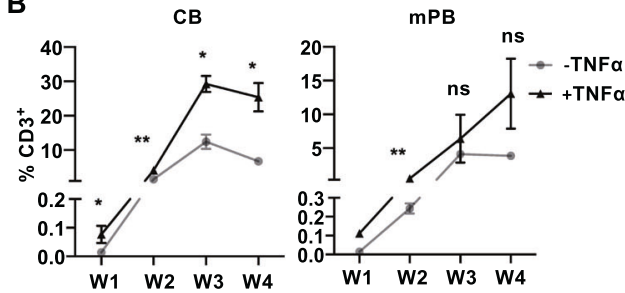

C

\begin{tabular}{|c|c|}
\hline TCRס & TCRY \\
\hline$\underline{V d 1-J d 1 V d 2-J d 1}$ & $\mathrm{Jg} 1.3 / 2.3$ \\
\hline Dd2-Jd1 $\mathrm{Dd2} 2 \mathrm{Dd} 3 \mathrm{Vd} 2-\mathrm{Dd} 3$ & $\underline{\mathrm{Jg} 1.1 / 2.1} \underline{\mathrm{JP}}$ \\
\hline
\end{tabular}

\begin{tabular}{cccc}
$T C R \beta$ \\
\hline$\underline{V b-J b 1}$ & $\underline{V b-J b 2}$ & $\underline{D b 2-J b 2}$ & $\underline{D b 1-J b 1}$ \\
$\underline{V b-J b 2}$ & & & $\underline{D b 1-J b 2}$
\end{tabular}

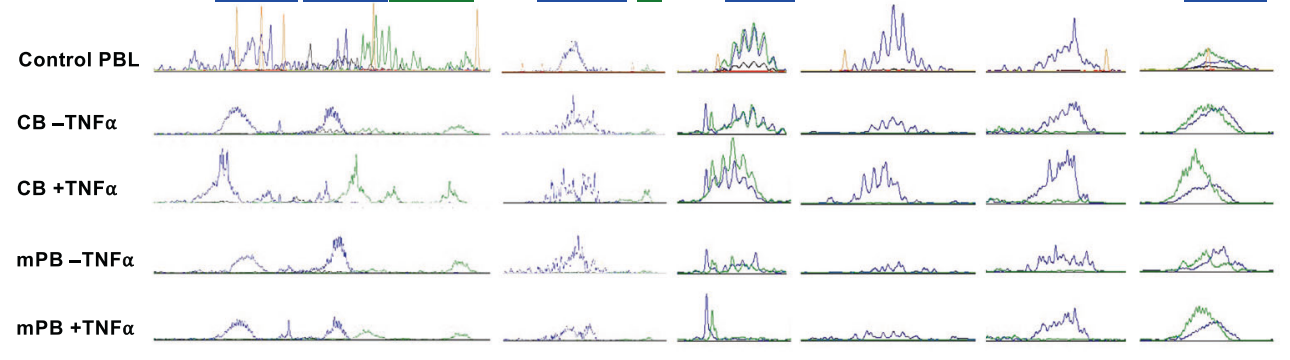

D

Thymi 4 weeks post-transplantation
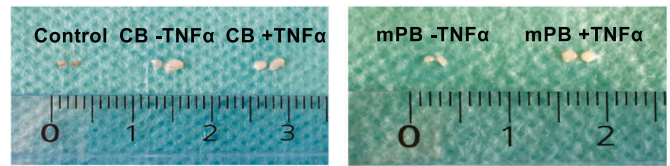

E

$\mathrm{CB}$
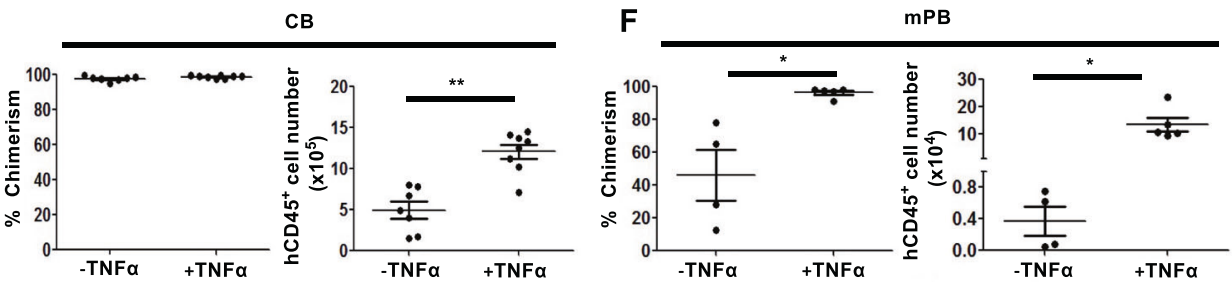

G

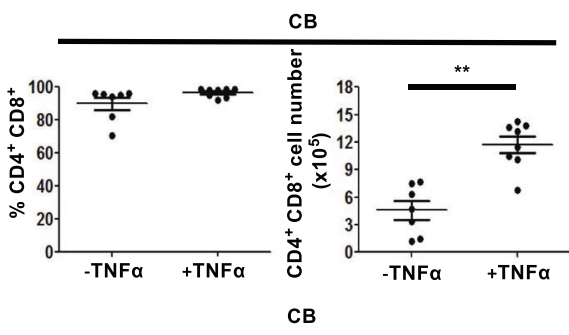

H
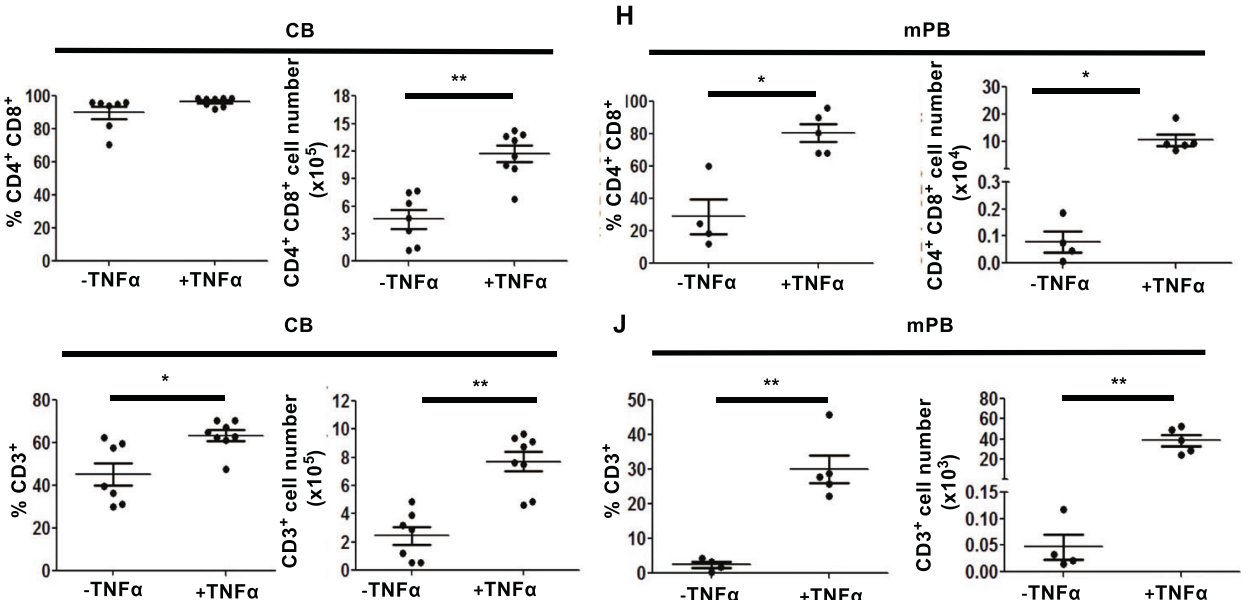

Fig. 5 TNF $\alpha$ enhances the in vitro and in vivo T-cell potential of $C D 7^{+}$HTLPs derived from $C B$ or mPB HSPCs. Graphs showing the mean frequencies of $\mathrm{CD}^{+}{ }^{+} \mathrm{CD}^{+}$cells $(\mathbf{A})$ and $\mathrm{CD}^{+}$cells $(\mathbf{B})$ obtained after $1,2,3$ and 4 weeks of coculture of day-7 CB or mPB HSPC-derived HTLPs (with or without TNF $\alpha$ treatment) with OP9-hDL1 stromal cells (mean $\pm \mathrm{SEM}, n=3$ ). The $p$ values were calculated using a paired two-tailed $t$ test: ${ }^{*} p \leq 0.05 ;{ }^{* *} p \leq 0.01 ;{ }^{* * *} p \leq 0.001$. C Analyses of TCR $\delta, \mathrm{TCR} \gamma$ and TCR $\beta$ rearrangements in T cells differentiated from CB or mPB CD7 ${ }^{+} \mathrm{HTLPs}^{*}$ after OP9-hDL1 coculture. Each peak represents the fluorescence intensity of the corresponding rearrangement loci; positive control: peripheral blood lymphocytes (PBLs). D Representative photographs of the thymus four weeks after intrahepatic injection of $5 \times 10^{5} \mathrm{CB}$ or mPB HSPC-derived HTLPs (cultured with or without TNF $\alpha$ treatment) into 1- to 4-day-old NSG mice. Graphs showing the chimerism and numbers of $\mathrm{hCD} 45^{+}$cells in the thymus of $\mathrm{CB}(\mathbf{E})$ and $\mathrm{mPB}(\mathbf{F}) \mathrm{HSPC}$-derived HTLP recipients. Graphs showing the frequencies and numbers of $\mathrm{CD}^{+} \mathrm{CD}^{+}$cells for CB-HTLP $(\mathbf{G})$ and mPB-HTLP $(\mathbf{H})$. Graphs showing the frequencies and numbers of CD3 $3^{+}$cells for CB-HTLP $(\mathbf{I})$ and mPBHTLP $(\mathbf{J})$. Each dot represents a recipient mouse. The $p$ values were calculated by one-way RM ANOVA: ${ }^{*} p \leq 0.05 ;{ }^{* *} p \leq 0.01$ 
A

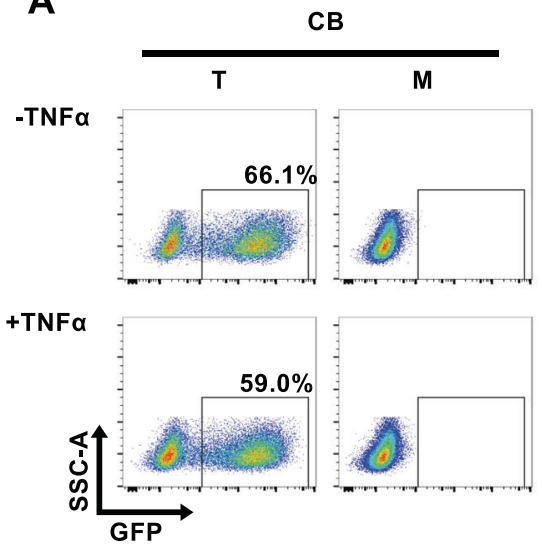

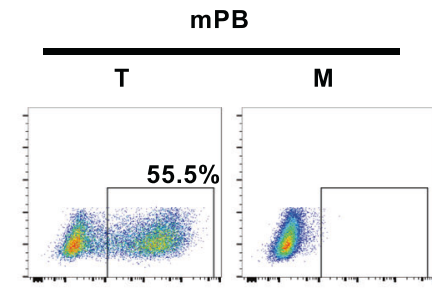

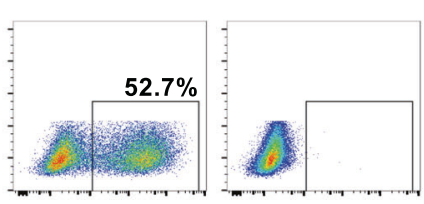

B

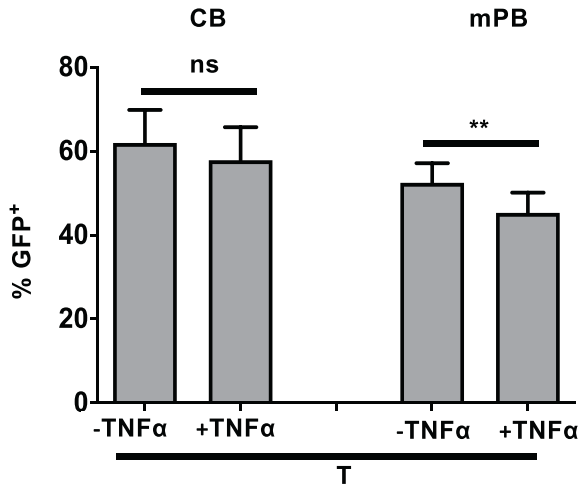

C

GFP $^{+}$cells

GFP- cells
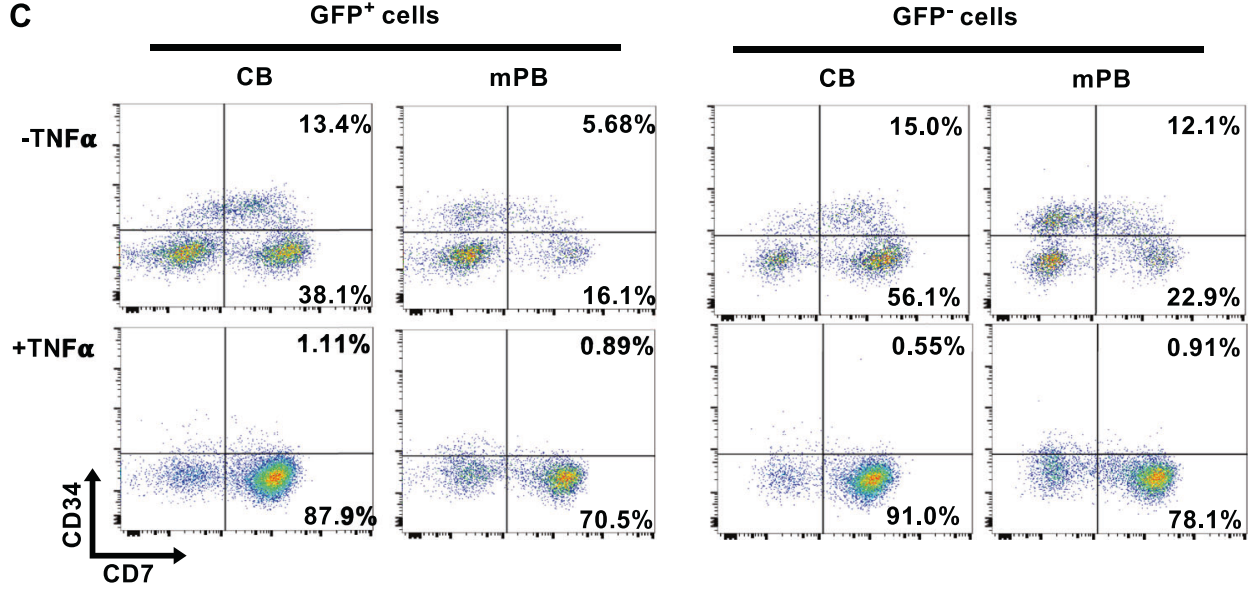

D

E
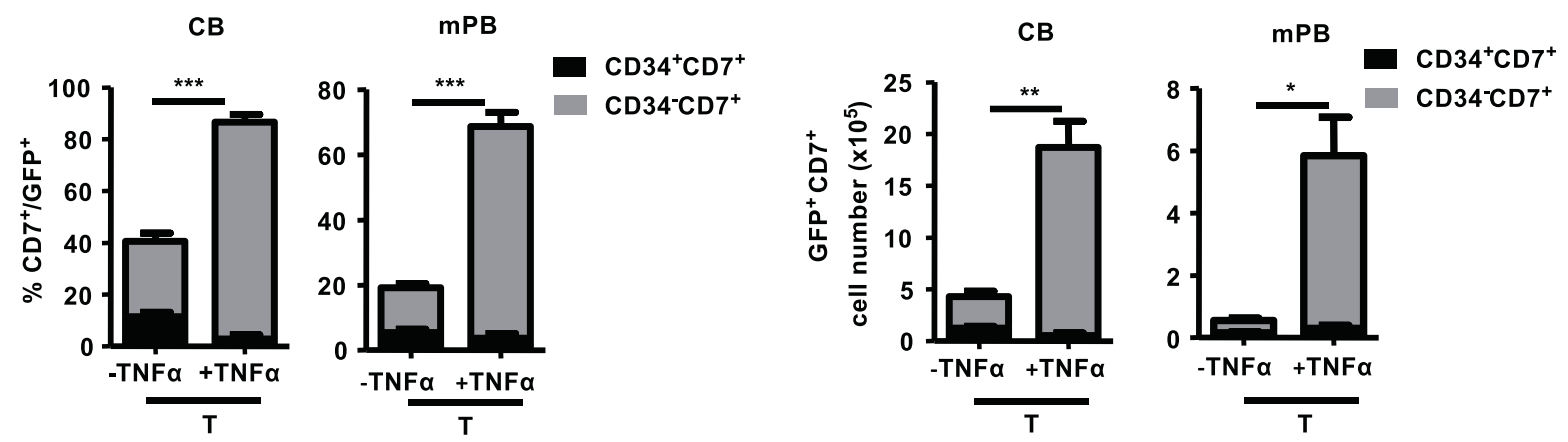

Fig. 6 Efficient generation of transduced HTLPs from TNF $\alpha$-supplemented DL-4 cultures of CB or mPB HSPCs. A A representative FACS plot of the transduction efficiency of CB or mPB HSPCs after transduction (T) or nontransduced mock (M) treatment with a GFP-encoding lentiviral vector and 7 days of DL-4 culture in the presence $(100 \mathrm{ng} / \mathrm{ml})$ or absence of TNF $\alpha$. B Graph showing transduction efficiencies (mean \pm SEM, $n=5)$. C A representative FACS plot of the phenotype of transduced $\left(\mathrm{GFP}^{+}\right)$(left panel) and nontransduced (GFP ${ }^{-}$) (right panel) cells, showing $\mathrm{CD}_{3} 4^{+/-} \mathrm{CD}^{+}$T-cell progenitor differentiation. Graphs showing the mean frequencies (D) and numbers (E) of transduced CD34 ${ }^{+/-} \mathrm{CD} 7^{+}$ progenitors after 7 days of culture under transduction conditions in the presence $(100 \mathrm{ng} / \mathrm{ml})$ or absence of TNF $\alpha$ (mean \pm SEM, $n=5)$. The $p$ values were calculated by one-way RM ANOVA: ${ }^{*} p \leq 0.05 ;{ }^{* *} p \leq 0.01 ;{ }^{* *} p \leq 0.001$

vector encoding a GFP reporter on DL-4/RetroNectin ${ }^{\circledR}$ and cultured for a total of 7 days in the presence or absence of TNFa. Analysis of the transduction efficiency (based on the expression of GFP) in the HTLP cultures showed that the HSPCs could be efficiently transduced (mean \pm SEM transduction efficiencies in the presence and absence of TNFa: $57.8 \pm 7.89 \%$ and $61.9 \pm 7.86 \%$ for $\mathrm{CB}$ and $45.3 \pm 4.84 \%$ and $52.5 \pm 4.66 \%$ for $\mathrm{mPB}$, respectively) (Fig. 6A,B). Although the addition of TNFa did not significantly affect the transduction efficiencies of CB HTLP cultures, it significantly decreased the transduction efficiencies of mPB HTLP 
cultures by 1.2 -fold (Fig. $6 \mathrm{~A}, \mathrm{~B}$ ). The transduced cells in HTLP cultures of $C B$ or mPB HSPCs were able to differentiate into $\mathrm{CD}^{+}$ HTLPs in the presence or absence of TNFa (Fig. $6 C, D$ ). Although the transduced $\mathrm{GFP}^{+}$cells showed decreased $\mathrm{CD}^{+} \mathrm{HTLP}$ frequencies compared to the nontransduced $\mathrm{GFP}^{-}$cells in cultures without TNFa, the $\mathrm{CD}^{+} \mathrm{HTLP}$ frequencies in $\mathrm{GFP}^{+}$and $\mathrm{GFP}^{-}$cells were similar in cultures supplemented with TNFa (Fig. 6C). As observed in the cultures without genetic manipulation, the frequencies of transduced $\mathrm{CD}^{+}$HTLPs were significantly higher for TNFa-supplemented cultures than for nonsupplemented cultures (mean \pm SEM frequencies in the presence and absence of TNFa: $80.682 \pm 2.4 \%$ vs. $36.67 \pm 4.52 \%$ for CB and $68.6 \pm 2.23 \%$ vs. $19.2 \pm 3.63 \%$ for $\mathrm{mPB}$ ) (Fig. $6 \mathrm{C}, \mathrm{D}$ ). The TNFa-induced increase in the frequency of transduced HTLPs was accompanied by a greater yield of transduced HTLPs (by factors of 4.3 and 10.5 for CB and $\mathrm{mPB}$, respectively) (Fig. 6E). These data indicate that large numbers of transduced genetically modified HTLPs can be efficiently generated in vitro in TNFa-supplemented HTLP cultures of $\mathrm{CB}$ or $\mathrm{mPB}$ HSPCs.

Enhanced T-cell potential of transduced genetically modified TNFa-exposed HTLPs

Upon OP9-hDL1 coculture, transduced $\mathrm{CD}^{+} \mathrm{CD} 8^{+}$DP cells appeared at week 1 in the transduced CB HTLP cocultures (regardless of TNFa treatment) and in the TNFa-treated transduced MPB HTLP coculture and at week 2 in the nontreated transduced MPB HTLP coculture (Fig. 7A and Supplementary Fig. S7A). In addition to accelerated T-cell differentiation, an elevated frequency of transduced DP cells was observed in the TNFa-treated MPB HTLP coculture compared to the nontreated counterpart (Fig. 7A and Supplementary Fig. S7A). Transduced $\mathrm{CD}^{+}$cells (expressing $\gamma \delta$ or $a \beta$ TCRs) were detected under all conditions from week 2 onwards, with higher proportions in transduced TNFa-exposed CB or mPB HTLP cocultures than in their nonexposed counterparts (Fig. 7B and Supplementary Fig. S7B). These data suggest that transduced TNFa-treated CB and MPB HTLPs differentiate more efficiently into $T$ cells than their untreated counterparts.

The constant expression of GFP (Fig. 7C) indicated stable transduction of HTLPs under all conditions. This observation was consistent with the stable vector copy numbers observed at week 0 (before the coculture) and at weeks 3 and 4 of coculture (Fig. 7D).

Next, we tested the in vivo T-cell potential of transduced HTLPs following intrahepatic transplantation into nonirradiated neonatal NSG mice. Four weeks after transplantation, human (h)CD45 ${ }^{+}$cells colonized the thymus to a similarly high extent $(>90 \%)$ in all the recipients (regardless of TNFa treatment and transduction), with the exception of one of the recipients of transduced nontreated HTLPs (Fig. 7E and Supplementary Fig. S7C). The proportions of transduced $\mathrm{hCD} 45^{+}$cells were less varied among the TNFa-treated HTLP recipients than among nontreated HTLP recipients (Fig. 7F and Supplementary Fig. S7D). Additionally, the transduced hCD $45^{+}$ cell count was 3.2-fold higher for TNFa-treated HTLPs than for nontreated HTLPs (Fig. 7G). Active thymopoiesis of transduced HTLPs (measured by the presence of transduced human $\mathrm{CD} 45^{+} \mathrm{CD}^{+} \mathrm{CD}^{+} \mathrm{DP}$ cells) was observed under both conditions (Fig. 7H and Supplementary Fig. S7E). Although the proportions of transduced DP and $\mathrm{CD}^{+}$cells were similar, their counts were significantly (3-fold and 3.3-fold increases, respectively) higher for TNFa-treated HTLPs (Fig. 7H-K and Supplementary Fig. S7E,F). Taken together, these data demonstrate that transduced genetically modified HTLPs can efficiently differentiate into transduced T cells both in vitro and in vivo. Furthermore, TNFa-treated HTLPs have a greater T-cell potential than nontreated HTLPs.

\section{DISCUSSION}

Adult HSPCs harvested from mPB are increasingly being used for related-donor and unrelated-donor HSCT, and this approach has several advantages over CB grafts. ${ }^{36,37}$ Adult mPB not only yields more HSPCs but can also be used to generate an autologous graft, reducing the risks of graft rejection and graft-versus-host disease. When compared with BM as a source of HSPCs, adult MPB requires does not require anesthesia, hospitalization or blood transfusion for collection; hence, the probability of a serious adverse event is very low. However, in regard to generating T-cell progenitors and thus accelerating T-cell recovery after HSCT, our previously published work highlighted a delay in T-cell progenitor commitment and a very low HTLP yield for MPB HSPCs in a DL-4 culture system. ${ }^{21}$ Hence, we screened a number of molecules (2phosphate-L-ascorbic acid, StemReginin 1, UM171, UM729 and TNFa) to improve cell yields and cell expansion in the DL-4 culture system, with a focus on mPB HSPC-derived progenitors. We found that the addition of TNFa to the DL-4 culture system specifically enhanced the generation of $\mathrm{CD}^{+}$HTLPs by increasing the survival and proliferation of $\mathrm{CD}^{+}$progenitors, resulting in a highly homogeneous cell product. These HTLPs differentiated very quickly and efficiently (with even better results obtained with $\mathrm{mPB}$ ) in vitro and in vivo.

Previously, Seet and coll. established an efficient method to generate mature T cells from multiple human HSPC sources using artificial thymic organoids under serum-free conditons. ${ }^{38}$ Another approach for the generation of murine and human T-cell progenitors from mouse fetal HSPCs and human CB HSPCs using immobilized DL-4 and vascular cell adhesion molecule 1 (VCAM-1) was also reported. ${ }^{39}$ Unlike these approaches, our TNFasupplemented immobilized DL-4 culture system generated high numbers of HTLPs from CB or mPB HSPCs.

Tumor necrosis factor alpha has a protective effect on HSPCs. The transplantation of lineage-negative BM cells from TNF receptor-deficient mice into wild-type recipients was shown to result in defective early engraftment and the loss of a lasting hematopoietic contribution from the host. ${ }^{40}$ Human HSPCs obtained from $\mathrm{BM}, \mathrm{CB}$ or $\mathrm{mPB}$ are highly resistant to TNFamediated apoptosis, whereas mature cells (such as $\mathrm{CD}^{+} \mathrm{T}$ cells, $\mathrm{CD} 19^{+} \mathrm{B}$ cells, and $\mathrm{CD}_{3}{ }^{+}$myeloid cells) are more susceptible. ${ }^{41-47}$ Interestingly, some researchers have identified a link between TNFa and thymopoiesis. As the key stimulus for NFKB signaling, $\mathrm{TNFa}$ is expressed in the thymic microenvironment by macrophages, thymic stromal cells, and thymocytes themselves. ${ }^{48,49}$ It has been reported that preincubation of $\mathrm{BM}$ - or $\mathrm{CB}$-derived $\mathrm{CD} 34^{+}$ cells with TNFa increases the generation of mature $T$ cells in an ex vivo murine fetal thymic culture system. ${ }^{27,28}$ The expression and activation of TNF receptor superfamily members, including TNFRII, as observed in our data, are also known to promote regulatory T-cell differentiation in murine thymocytes. ${ }^{50}$ Mechanistically, TNFa was shown to upregulate CD127 (the interleukin (IL)-7 receptor alpha-chain) in a small fraction of BM-derived $\mathrm{CD}^{+} 4^{+} \mathrm{HSPCs}$ and the T-cell commitment factor Gata3 in a small fraction of CB-derived $\mathrm{CD} 34^{+}$HSPCs. However, none of these studies examined the specific effects of TNFa during the early stages of T-cell commitment. In the present study, we demonstrated that TNFa specifically influences the proliferation and survival (and thus the frequency and yield) of early and late $C D 7^{+}$ progenitors. The effects of TNFa are DL-4 dependent and seem to rely on activation of the NFkB pathway, in line with other studies showing the positive effect of Notch on NFkB activation. ${ }^{51}$ These effects thus combine (i) accelerated T-cell differentiation through upregulated GATA3 and BCL11B expression, (ii) decreased apoptosis achieved by upregulating the expression of antiapoptotic molecules such as $\mathrm{BCl}-2$ and $\mathrm{Mcl}-1$ in $\mathrm{CD}^{+}$cells (our data) and potentially cellular Inhibitor of Apoptosis Protein 1 or $2,^{52}$ and (iii) accelerated entry into the cell cycle, possibly through p53 pathway inhibition. Further investigations of the mechanisms of action involving TNFa are warranted to test these hypotheses.

We scaled up our TNFa-supplemented high-performance $\mathrm{CD}^{+}$ HTLP culture system for potential use in clinical applications. 
A

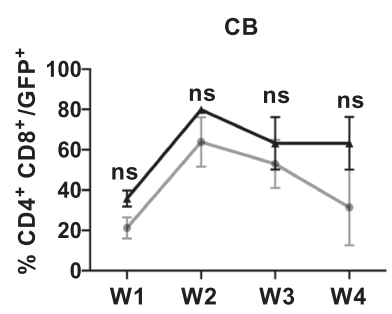

C

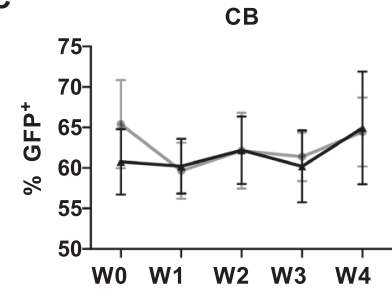

$\mathbf{E}$

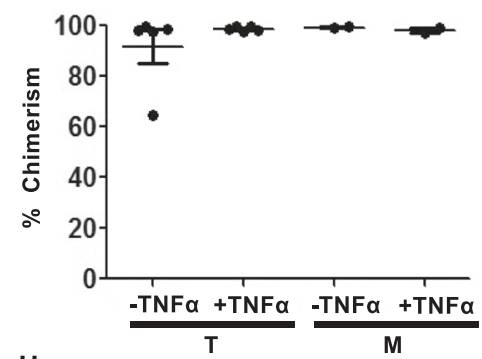

H
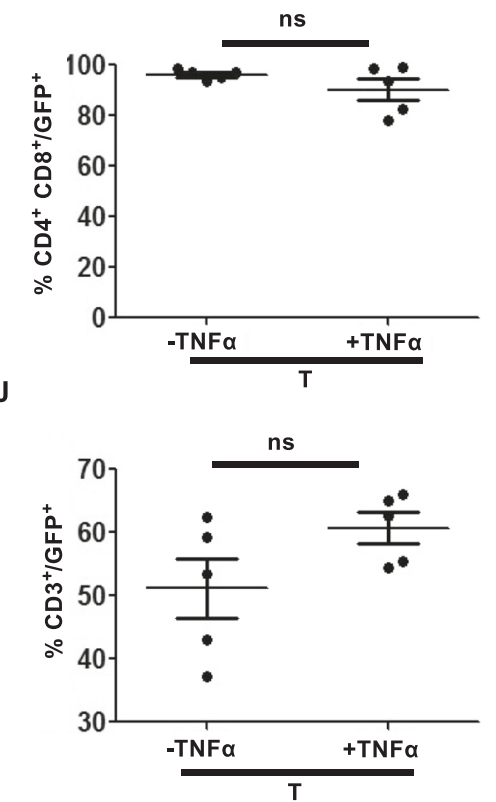

B
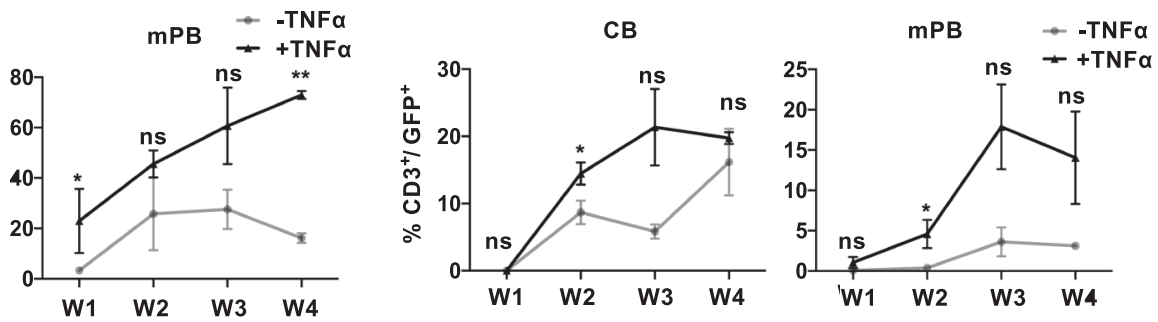

D
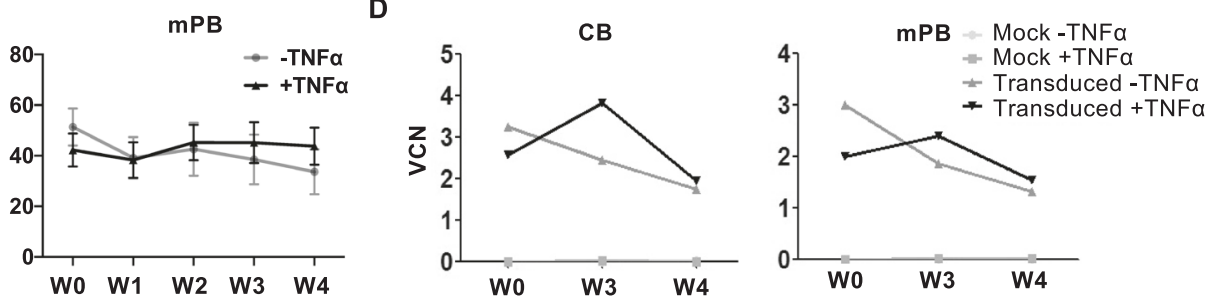

$\mathbf{F}$

G

hCD45 ${ }^{+}$cells
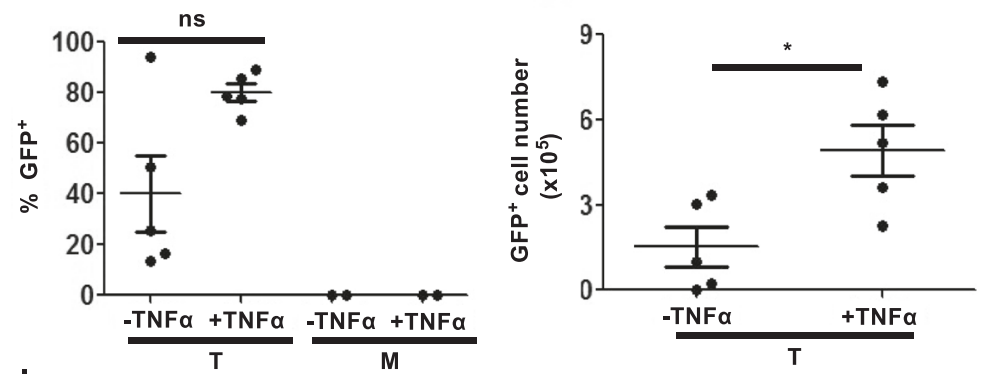

I
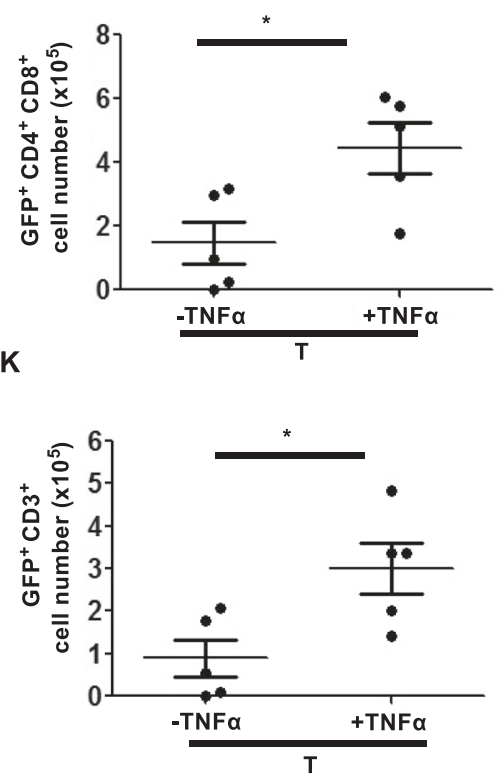

Fig. 7 Enhanced in vitro and in vivo T-cell potential of transduced $C D 7^{+}$HTLPs. Graphs showing the mean frequencies of transduced $\mathrm{CD}^{+} \mathrm{CD}^{+}$cells $(\mathbf{A})$ and $\mathrm{CD}^{+}$cells (B) obtained after $1,2,3$ and 4 weeks of coculture of day-7 CB or mPB HSPC-derived transduced HTLPs (with or without TNF $\alpha$ treatment) with OP9-hDL1 stromal cells (mean $\pm \mathrm{SEM}, n=3$ ). The $p$ values were calculated using a paired two-tailed $t$ test: ${ }^{*} p \leq 0.05 ;{ }^{* *} p \leq 0.01$. C A graph showing the mean frequencies of transduced cells during 4 weeks of OP9-hDL1 coculture (mean \pm SEM, $n=3)$. D A graph representing the vector copy number per cell of OP9-hDL1 cell-cocultured transduced CB or mPB HTLPs at the indicated weeks of coculture. E Graphs showing the chimerism of hCD45 ${ }^{+}$cells in the thymus of recipient NSG mice four weeks after intrahepatic injection of $5 \times 10^{5}$ CB HSPC-derived transduced (T) or nontransduced mock (M) HTLPs (cultured with or without TNF $\alpha$ treatment) into 1- to 4day-old NSG neonates. Graphs showing the frequencies (F) and numbers (G) of transduced hCD45 ${ }^{+}$cells in the thymus of NSG mouse recipients. Graphs showing the frequencies $(\mathbf{H})$ and numbers (I) of transduced $\mathrm{CD} 4^{+} \mathrm{CD} 8^{+}$cells in the thymus of recipient mice. Graphs showing the frequencies $(\mathbf{J})$ and numbers $(\mathbf{K})$ of transduced $\mathrm{CD}^{+}$cells in the thymus of recipient mice. Each dot represents a recipient mouse. The $p$ values were calculated by one-way RM ANOVA: ${ }^{*} p \leq 0.05$ 
Indeed, we have shown that the outcome of $\mathrm{CD}^{+} \mathrm{HTLP}$ generation in a preclinical setting (i.e., with clinical-grade reagents) is similar to that obtained in the research-grade system described in detail above. Moreover, karyotyping and in vivo tumorigenicity studies of the cell product suggest that $\mathrm{CD}^{+}$ HTLPs can be used safely in the clinic. The ability of transplanted $\mathrm{CD}^{+}$progenitors generated in the present culture system to treat T-cell deficiencies will be investigated in a forthcoming clinical trial (NCT03879876) that has been approved by the French Drug Agency. Twelve SCID patients will receive haploidentical CD34 HSPCs and a single dose of HTLPs. The study's primary objective is to assess the overall safety and dose-related toxicity of this protocol. The secondary objectives include assessments of graft rejection, the presence of naïve $C D 4^{+} T$ cells at 6 months, the time course of T-cell reconstitution, the incidence of infections, the relapse rate, and overall survival.

We are also initiating a clinical trial of CB-based HSCT in adult patients with leukemia who will receive two $C B$ grafts: one prepared in the TNFa-supplemented DL- 4 culture system and one that has not been manipulated. These two trials will provide valuable information on the feasibility and safety of HTLP engraftment and the comparative advantages or disadvantages of mPB- vs. CB-derived HTLPs.

Tumor necrosis factor alpha mediates the inflammatory response; ${ }^{53}$ hence, agents that block TNFa activity are widely used to treat inflammatory diseases and certain autoimmune diseases (such as rheumatoid arthritis). On the other hand, tumor necrosis factor alpha is secreted in response to viral infections and has a protective role in host defense against viral infections. Not surprisingly, anti-TNFa therapy increases patient susceptibility to infection by various viruses (e.g., HIV and Epstein-Barr virus) by countering the protective antiviral effect of this cytokine. ${ }^{54,55}$ This factor has long been known to have antiviral activity mediated by killing infected cells directly or by increasing uninfected cell resistance to infection. ${ }^{56-59}$ These observations suggest that the presence of TNFa is not compatible with lentiviral transduction. In the present study, however, we were able to successfully transduce CB and mPB HSPCs under TNFa-supplemented DL-4 culture conditions and thus generate large numbers of transduced HTLPs. Furthermore, compared to nontransduced cells, transduced HTLPs were as capable of differentiating into T cells in vitro and in vivo. The combination of the protective effect of TNFa on HSPCs and a specific Notch-dependent effect on HTLPs might explain this result.

Therefore, the TNFa-supplemented DL-4 culture system offers a suitable platform for gene correction approaches and establishes new opportunities for developing personalized treatments based on genetically modified T-lymphoid progenitors.

In particular, our culture system could lead to new CAR T-cell approaches based on the transplantation of CAR-modified HTLPs and the generation of naïve and fully functional CAR-modified $T$ cells in patients.

\section{ACKNOWLEDGEMENTS}

The authors thank Sven Kracker and Antoine Toubert for reading the manuscript and engaging in helpful discussions; Ellen Rothenberg for fruitful discussions; Anne Puel for helpful discussions of some experiments; and Christine Bole for RNA-sequencing contributions. We also thank the staff at the Imagine Institute's genomics platform, bioinformatic, flow cytometry and animal facilities. This work was supported by the French Institut National de la Santé et de la Recherche Médicale (INSERM), the European Union Seventh Framework Programme under grant agreements No 269037 and No 261387, the European Union's Horizon 2020 research and innovation programme under grant agreement No 666908, and state funding from the Agence Nationale de la Recherche under the "Investissement d'avenir" program (ANR-10-IAHU01 ) and the Paris lle-de-France Region under the "DIM Thérapie génique" initiative. $\mathrm{K}$. M. was funded by the China Scholarship Council and the Fondation pour la Recherche Médicale. A.C. was funded by the French Institut National du Cancer.

\section{AUTHOR CONTRIBUTIONS}

R.D.M. and K.M. designed and conducted experiments, analyzed data, and wrote the manuscript. S.L., A.C., J.O. C.d.C., A.J. and J.T. performed and analyzed some experiments. N. C analyzed RNA-seq data. A.C. and V.A. performed and analyzed TCR rearrangement assays. A.R., L.S., T.T., F.J.T.S., and E.S. participated in discussions and read the manuscript. J.Z. and F.P. reviewed the manuscript for critical content. M.C. discussed the data and reviewed the manuscript for critical content. C.L.P. and T. S supervised the research and reviewed the manuscript. I.A. designed and supervised the overall research and reviewed the manuscript for critical content.

\section{ADDITIONAL INFORMATION}

Supplementary information The online version contains supplementary material available at https://doi.org/10.1038/s41423-021-00706-8.

Competing interests: I.A. and M.C. are the co-founders of the biotech company Smart Immune. T.S. and L.S. are currently working for Smart Immune, Plc. The authors have no additional financial interests.

\section{REFERENCES}

1. Miliotou, A. N. \& Papadopoulou, L. C. CAR T-cell therapy: a new era in cancer immunotherapy. Curr. Pharm. Biotechnol. 19, 5-18 (2018).

2. Qi, J., Ding, C., Jiang, X. \& Gao, Y. Advances in developing CAR T-cell therapy for HIV cure. Front. Immunol. 11, 361 (2020).

3. Wang, Z. et al. Prospects of the use of cell therapy to induce immune tolerance. Front. Immunol. 11, 792 (2020).

4. Zhang, Q. et al. Chimeric antigen receptor (CAR) treg: a promising approach to inducing immunological tolerance. Front. Immunol. 9, 2359 (2018).

5. Schuster, S. J. et al. Chimeric antigen receptor T cells in refractory B-cell lymphomas. N. Engl. J. Med. 377, 2545-2554 (2017).

6. Qasim, W. Allogeneic CAR T cell therapies for leukemia. Am. J. Hematol. 94 S50-S54 (2019).

7. Chen, H. et al. Management of cytokine release syndrome related to CAR-T cell therapy. Front. Med. 13, 610-617 (2019).

8. Clave, E. et al. Thymic function recovery after unrelated donor cord blood or Tcell depleted HLA-haploidentical stem cell transplantation correlates with leukemia relapse. Front. Immunol. 4, 54 (2013).

9. Bartelink, I. H. et al. Immune reconstitution kinetics as an early predictor for mortality using various hematopoietic stem cell sources in children. Biol. Blood Marrow Transplant. 19, 305-313 (2013).

10. Storek, J. et al. Allogeneic peripheral blood stem cell transplantation may be associated with a high risk of chronic graft-versus-host disease. Blood 90 , 4705-4709 (1997).

11. Chaudhry, M. S., Velardi, E., Malard, F. \& van den Brink, M. R. M. Immune reconstitution after allogeneic hematopoietic stem cell transplantation: time to $\mathrm{T}$ Up the thymus. J. Immunol. 198, 40-46 (2017).

12. Hozumi, K. et al. Delta-like 4 is indispensable in thymic environment specific for $T$ cell development. J. Exp. Med. 205, 2507-2513 (2008).

13. Koch, U. et al. Delta-like 4 is the essential, nonredundant ligand for Notch1 during thymic T cell lineage commitment. J. Exp. Med. 205, 2515-2523 (2008).

14. Taghon, T., Waegemans, E. \& Van de Walle, I. Notch signaling during human T cell development. Curr. Top. Microbiol. Immunol. 360, 75-97 (2012).

15. Hosokawa, H. \& Rothenberg, E. V. Cytokines, transcription factors, and the initiation of T-cell development. Cold Spring Harb. Perspect. Biol. 10, a028621 (2018).

16. Six, E. M. et al. Cytokines and culture medium have a major impact on human in vitro T-cell differentiation. Blood Cells Mol. Dis. 47, 72-78 (2011).

17. Schmitt, T. M. \& Zúñiga-Pflücker, J. C. Thymus-derived signals regulate early T-cell development. Crit. Rev. Immunol. 25, 141-159 (2005).

18. Hao, Q.-L. et al. Human intrathymic lineage commitment is marked by differential CD7 expression: identification of CD7- lympho-myeloid thymic progenitors. Blood 111, 1318-1326 (2008).

19. Weerkamp, F. et al. Human thymus contains multipotent progenitors with T/B lymphoid, myeloid, and erythroid lineage potential. Blood 107, 3131-3137 (2006).

20. Reimann, C. et al. Human T-lymphoid progenitors generated in a feeder-cell-free Delta-like-4 culture system promote T-cell reconstitution in NOD/SCID/ $\mathrm{\gamma c}(-/-)$ mice. Stem Cells 30, 1771-1780 (2012).

21. Simons, L. et al. Generation of adult human T-cell progenitors for immunotherapeutic applications. J. Allergy Clin. Immunol. 141, 1491-1494.e4 (2018).

22. Carlin, S. M., Ma, D. D. \& Moore, J. J. T-cell potential of human adult and cord blood hemopoietic stem cells expanded with the use of aryl hydrocarbon receptor antagonists. Cytotherapy 15, 224-230 (2013).

23. Boitano, A. E. et al. Aryl hydrocarbon receptor antagonists promote the expansion of human hematopoietic stem cells. Science 329, 1345-1348 (2010). 
24. Singh, J. et al. Generation and function of progenitor T cells from StemRegenin-1expanded CD34+ human hematopoietic progenitor cells. Blood Adv. 3, 2934-2948 (2019).

25. Fares, I. et al. Pyrimidoindole derivatives are agonists of human hematopoietic stem cell self-renewal. Science 345, 1509-1512 (2014).

26. Huijskens, M. J. A. J. et al. Technical advance: ascorbic acid induces development of double-positive T cells from human hematopoietic stem cells in the absence of stromal cells. J. Leukoc. Biol. 96, 1165-1175 (2014).

27. Weekx, S. F. et al. Generation of T cells from adult human hematopoietic stem cells and progenitors in a fetal thymic organ culture system: stimulation by tumor necrosis factor-alpha. Blood 95, 2806-2812 (2000).

28. Smits, K. et al. Tumor necrosis factor promotes T-cell at the expense of B-cell lymphoid development from cultured human $\mathrm{CD} 34+$ cord blood cells. Exp. Hematol. 35, 1272-1278 (2007).

29. Six, E. M. et al. A human postnatal lymphoid progenitor capable of circulating and seeding the thymus. J. Exp. Med 204, 3085-3093 (2007).

30. van Dongen, J. J. M. et al. Design and standardization of PCR primers and protocols for detection of clonal immunoglobulin and T-cell receptor gene recombinations in suspect lymphoproliferations: report of the BIOMED-2 Concerted Action BMH4-CT98-3936. Leukemia 17, 2257-2317 (2003).

31. Rothenberg, E. V. Transcriptional drivers of the T-cell lineage program. Curr. Opin. Immunol. 24, 132-138 (2012).

32. Portt, L., Norman, G., Clapp, C., Greenwood, M. \& Greenwood, M. T. Anti-apoptosis and cell survival: a review. Biochim. Biophys. Acta 1813, 238-259 (2011).

33. Thomas, L. W., Lam, C. \& Edwards, S. W. Mcl-1; the molecular regulation of protein function. FEBS Lett. 584, 2981-2989 (2010).

34. André, l. et al. Ex vivo generated lymphoid progenitors for immune reconstitution in the context of allogeneic transplantation and gene therapy [Abstract]. Focis $W$. 50, 74 (2019).

35. Körner, M., Tarantino, N. \& Debré, P. Constitutive activation of NF-kB in human thymocytes. Biochemical Biophysical Res. Commun. 181, 80-86 (1991).

36. Robin, M. et al. Comparison of unrelated cord blood and peripheral blood stem cell transplantation in adults with myelodysplastic syndrome after reducedintensity conditioning regimen: a collaborative study from Eurocord (Cord blood Committee of Cellular Therapy \& Immunobiology Working Party of EBMT) and Chronic Malignancies Working Party. Biol. Blood Marrow Transplant. 21, 489-495 (2015).

37. Yasui, K., Matsumoto, K., Hirayama, F., Tani, Y. \& Nakano, T. Differences between peripheral blood and cord blood in the kinetics of lineage-restricted hematopoietic cells: implications for delayed platelet recovery following cord blood transplantation. Stem Cells 21, 143-151 (2003).

38. Seet, C. S. et al. Generation of mature T cells from human hematopoietic stem and progenitor cells in artificial thymic organoids. Nat. Methods 14, 521-530 (2017).

39. Shukla, S. et al. Progenitor T-cell differentiation from hematopoietic stem cells using Delta-like-4 and VCAM-1. Nat. Methods 14, 531-538 (2017).

40. Pearl-Yafe, M. et al. Tumor necrosis factor receptors support murine hematopoietic progenitor function in the early stages of engraftment. Stem Cells 28, 1270-1280 (2010)

41. Pearl-Yafe, M. et al. Expression of Fas and Fas-ligand in donor hematopoietic stem and progenitor cells is dissociated from the sensitivity to apoptosis. Exp. Hematol. 35, 1601-1612 (2007).

42. Mizrahi, K. et al. Regulatory functions of TRAIL in hematopoietic progenitors: human umbilical cord blood and murine bone marrow transplantation. Leukemia 24, 1325-1334 (2010).

43. Fukuda, S. \& Pelus, L. M. Regulation of the inhibitor-of-apoptosis family member survivin in normal cord blood and bone marrow $\mathrm{CD} 34(+)$ cells by hematopoietic growth factors: implication of survivin expression in normal hematopoiesis. Blood 98, 2091-2100 (2001).

44. Gaur, U. \& Aggarwal, B. B. Regulation of proliferation, survival and apoptosis by members of the TNF superfamily. Biochem. Pharmacol. 66, 1403-1408 (2003).

45. Nagafuji, K., Takenaka, K., Shibuya, T., Harada, M. \& Niho, Y. Fas antigen (CD95) and hematopoietic progenitor cells. Leuk. Lymphoma 24, 43-56 (1996).

46. Backx, B., Broeders, L., Bot, F. J. \& Löwenberg, B. Positive and negative effects of tumor necrosis factor on colony growth from highly purified normal marrow progenitors. Leukemia 5, 66-70 (1991).

47. Mizrahi, K., Yaniv, I., Ash, S., Stein, J. \& Askenasy, N. Apoptotic signaling through Fas and TNF receptors ameliorates GVHD in mobilized peripheral blood grafts. Bone Marrow Transplant. 49, 640-648 (2014).

48. Giroir, B. P., Brown, T. \& Beutler, B. Constitutive synthesis of tumor necrosis factor in the thymus. Proc. Natl Acad. Sci. USA. 89, 4864-4868 (1992).

49. Bichele, R., Kisand, K., Peterson, P. \& Laan, M. TNF superfamily members play distinct roles in shaping the thymic stromal microenvironment. Mol. Immunol. 72, 92-102 (2016).

50. Mahmud, S. A. et al. Costimulation via the tumor-necrosis factor receptor superfamily couples TCR signal strength to the thymic differentiation of regulatory T cells. Nat. Immunol. 15, 473-481 (2014).

51. Osipo, C., Golde, T. E., Osborne, B. A. \& Miele, L. A. Off the beaten pathway: the complex cross talk between Notch and NF-kappaB. Lab. Invest. 88, 11-17 (2008).

52. Wang, C. Y., Mayo, M. W., Korneluk, R. G., Goeddel, D. V. \& Baldwin, A. S. NFkappaB antiapoptosis: induction of TRAF1 and TRAF2 and C-IAP1 and C-IAP2 to suppress caspase-8 activation. Science 281, 1680-1683 (1998).

53. Rahman, M. M. \& McFadden, G. Modulation of tumor necrosis factor by microbial pathogens. PLoS Pathog. 2, e4 (2006).

54. Kim, S. Y. \& Solomon, D. H. Tumor necrosis factor blockade and the risk of viral infection. Nat. Rev. Rheumatol. 6, 165-174 (2010).

55. Ali, T. et al. Clinical use of anti-TNF therapy and increased risk of infections. Drug Health. Patient Saf. 5, 79-99 (2013).

56. Mestan, J. et al. Antiviral effects of recombinant tumour necrosis factor in vitro. Nature 323, 816-819 (1986).

57. Herbein, G., Montaner, L. J. \& Gordon, S. Tumor necrosis factor alpha inhibits entry of human immunodeficiency virus type 1 into primary human macrophages: a selective role for the 75-kilodalton receptor. J. Virol. 70, 7388-7397 (1996).

58. Lane, B. R. et al. TNF-alpha inhibits HIV-1 replication in peripheral blood monocytes and alveolar macrophages by inducing the production of RANTES and decreasing C-C chemokine receptor 5 (CCR5) expression. J. Immunol. 163, 3653-3661 (1999).

59. Wong, G. H. \& Goeddel, D. V. Tumour necrosis factors alpha and beta inhibit virus replication and synergize with interferons. Nature 323, 819-822 (1986).

(C) Open Access This article is licensed under a Creative Commons Attribution 4.0 International License, which permits use, sharing, adaptation, distribution and reproduction in any medium or format, as long as you give appropriate credit to the original author(s) and the source, provide a link to the Creative Commons license, and indicate if changes were made. The images or other third party material in this article are included in the article's Creative Commons license, unless indicated otherwise in a credit line to the material. If material is not included in the article's Creative Commons license and your intended use is not permitted by statutory regulation or exceeds the permitted use, you will need to obtain permission directly from the copyright holder. To view a copy of this license, visit http://creativecommons. org/licenses/by/4.0/.

(c) The Author(s) 2021 